\title{
Seismic bearing capacity of shallow strip footing embedded in slope resting on two-layered soil
}

https://doi.org/10.2478/sgem-2021-0021

Received December 15, 2020; accepted June 20, 2021

\begin{abstract}
In this paper,the limit equilibrium method with the pseudo-static approach is developed in the evaluation of the influence of slope on the bearing capacity of a shallow foundation. Particle swarm optimisation (PSO) technique is applied to optimise the solution. Minimum bearing capacity coefficients of shallow foundation near slopes are presented in the form of a design table for practical use in geotechnical engineering. It has been shown that the seismic bearing capacity coefficients reduce considerably with an increase in seismic coefficient. Besides, the magnitude of bearing capacity coefficients decreases further with an increase in slope inclination.
\end{abstract}

Keywords: Pseudo-static, Particle swarm optimisation, Bearing capacity coefficient, Slope inclination, Limit equilibrium

\section{Literature Review}

Many researchers analysed the bearing capacity based on the static method in which the bearing capacity coefficients were calculated based on static loads on the footings and the weight of the soil in both active and passive conditions. The classical bearing capacity theories started from Rankine (1857), Prandtl (1921), Terzaghi (1943), Meyerhof (1957), Saran et al. (1989) and many others who extensively studied the bearing capacity of shallow footings for static loading case. Terzaghi's bearing capacity theory (1943) was the first general theory for the bearing capacity of soils. Okabe (1924) and Mononobe and Matsuo (1929) were the pioneers in the inclusion of 'seismicity' in the design of structures. IS: 1893-1984(Part-3) has also adopted the Mononobe and Okabe method for the determination of seismic active and passive earth pressure behind the re-

\footnotetext{
*Corresponding Author: Litan Debnath, S.M. ASCE: Research Scholar, Civil Engineering Department, National Institute of Technology Agartala, PIN-799046, INDIA, E-mail: litandbnth4@gmail.com
}

taining wall. Sarma and lossifelis (1990), Richards et al. (1993), Budhu and Al-Karni (1993) and Kumar and Kumar (2003) considered the seismic forces both on the structures and on the supporting soil mass, which were not considered by Meyerhof (1957). Researchers like Dormieux and Pecker (1995), Paolucci and Pecker (1997), Soubra (1997), Kumar and Rao (2002), Kumar (2003) and Choudhury and Subba Rao (2005) studied the seismic bearing capacity of shallow footings for horizontal ground. Sawada et al. (1994), Sarma (1999) and Askari and Farzaneh (2003) gave the solution for seismic bearing capacity of shallow foundations near the sloping ground. Again, some work for surface footing on the sloping ground was carried out by Zhu (2000), Kumar and Kumar (2003) and Kumar and Rao (2003) using limit equilibrium analysis, method of characteristics, etc. Choudhury and Rao (2006),Castelli and Lentini (2012), Farzaneh and Askari (2013) and Chakraborty and Kumar (2014) determined the seismic bearing capacity of a shallow foundation embedded in sloping ground by using the theorem of limit equilibrium method and limit analysis in conjunction with finite elements and non-linear optimisation technique, respectively.In their analysis, it was found that on increasing slope inclination, the bearing capacity decreased. But the researchers did not analyse the bearing capacity on layered soil.Yamamoto (2010) investigated seismic bearing capacity coefficients of spread and embedded foundations near slope in the analytical method. The pseudostatic approach was used, and the seismic forces consisted of a horizontal load applied to the foundation and inertia of a soil mass. Chakraborty and Kumar (2013) evaluated the bearing capacity factor on the sloping ground by applying lower bound (LB) finite element limit analysis in conjunction with non-linear optimisation. Baazouzi et al. (2016) studied the numerical analysis of the bearing capacity for a strip footing near a cohesionless slope and subjected to a centred load using the finite difference code. Button (1953) was the first to analyse the bearing capacity of strip footing on two layers of clay under static loading conditions. In this analysis, it was postulated that failure surface at the ultimate load is cylindrical, where the centre of the cylindrical curve lies at the edge of the footing. 
Meyerhof and Hanna (1978) considered the case of footing reposing in various layers overlaying a strong soil deposit. Michalowski and Shi (1995) applied the kinematic approach of limit analysis to account for the limit pressure under footings to ascertain the bearing capacity of footings reposing on two-layered soil. Purushothamaraj et al. (1974) analysed the bearing capacity of shallow substratum utilising the upper bound (UB) limit analysis theorem. From all these literature surveys, it is seen that the bearing capacity of shallow foundation embedded in slope on layered soil is still limited. In the present analysis,the seismic bearing capacity of strip footing embedded in slope on two-layered soil has been analysed by using the limit equilibrium method with the pseudo-static approach.

\section{Methodology}

A strip footing having a width $B_{0}$ is assumed to be on the top of a two-layered $c-\phi$ soil as shown in Fig. 1. The footing (Fig. 2) having base AM is embedded in a sloping ground DY with an inclination $i$ to the horizontal ground surface. The footing is resting on two-layered c- $\phi$ soil. Homogeneous, isotropic c- $\phi$ soil with surcharge load along with the sloping ground is assumed in the analysis. Soil is assumed to be a rigid, perfectly plastic medium satisfying the Mohr-Coulomb failure criterion.Let the footing be at a depth of $\left(D_{\mathrm{f}}\right)$ below the ground surface (Fig. 2). Load $\left(P_{1}\right)$ acts along the centre line of the footing. For shallow foundation $\left(\mathrm{D}_{\mathrm{f}} \leq \mathrm{B}_{0}\right)$, the overburden pressure is idealised here as a triangular load distributionthat acts over the length of $\mathrm{RY}$ at an angle of inclination (i). From the concept of Debnath and Ghosh (2018), the two main regions, active wedge and passive wedge, are thereby assumed to be acoulomb failure mechanism as shown in Fig. 2. The active region gives an active lateral thrust $\mathrm{P}_{\mathrm{A}}$ pushing against the passive resistance $\mathrm{P}_{\mathrm{p}}$. The wall frictional angle between the active and passive zones is denoted as $\delta$. The active and passive zones are inclined at an angle $\alpha_{A 1}, \alpha_{A 2}, \alpha_{p 1} \alpha_{p 2}$, respectively. The detailed free body diagram of the active zone and passive zone is shown in Figs 3-6. From the equilibrium of the two wedges, the active pressure and passive resistance will be equal. Then, by equating the active pressure and passive resistance, the authors found out the maximum load acting on the foundation. After optimisation of the load $p_{L}$ by particle swarm optimisation (PSO) technique, the authors found out the minimum resistance. Parameters involved in the present study are as follows: $c_{1}=$ cohesion of soil in the top layer, $c_{2}=$ cohesion of soil in the bottom layer, $\phi_{1}=$ angle of friction of soil in the top

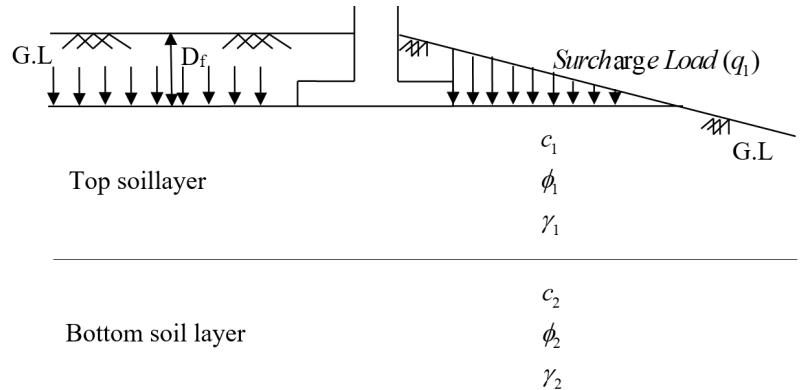

Figure 1: Geometry of footing on two-layered soil profile.

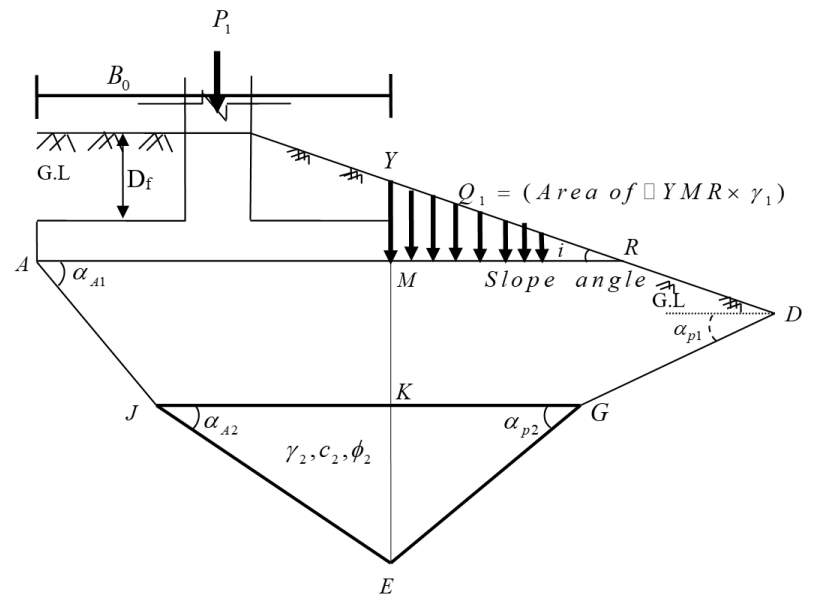

Figure 2: Failure mechanism and wedges assumed in present analysis.

layer, $\phi_{2}=$ angle of friction of soil in the bottom layer, $\gamma_{1}=$ unit weight of soil in the top layer, $\gamma_{2}=$ unit weight of soil in the bottom layer, $\alpha_{A 1}=$ angle of slip surface at the top layer in the active zone, $\alpha_{A 2}=$ angle of slip surface at the bottom layer in the active zone, $\alpha_{p 1}=$ angle of slip surface at the top layer in the passive zone, $\alpha_{p 2}=$ angle of slip surface at the bottom layer in the passive zone, $\delta_{i}=$ friction angle along the surface between active and passive zones at the $\mathrm{i}^{\text {th }}$ layer.

\subsection{Active pressure at the top layer}

As shown in Fig. 3, wedge AMKJ is a known active wedgethat is posited at the top layer, giving pressure to the passive wedge. The weight of the wedge

$$
W_{A}=\frac{2 B_{0}-h_{1} \cot \alpha_{A 1}}{2} h_{1} \gamma_{1},
$$

with the length of JK being equal to

$$
\left(B_{0}-h_{1} \cot \alpha_{A 1}\right)
$$

Total load acting on the foundation is given by 


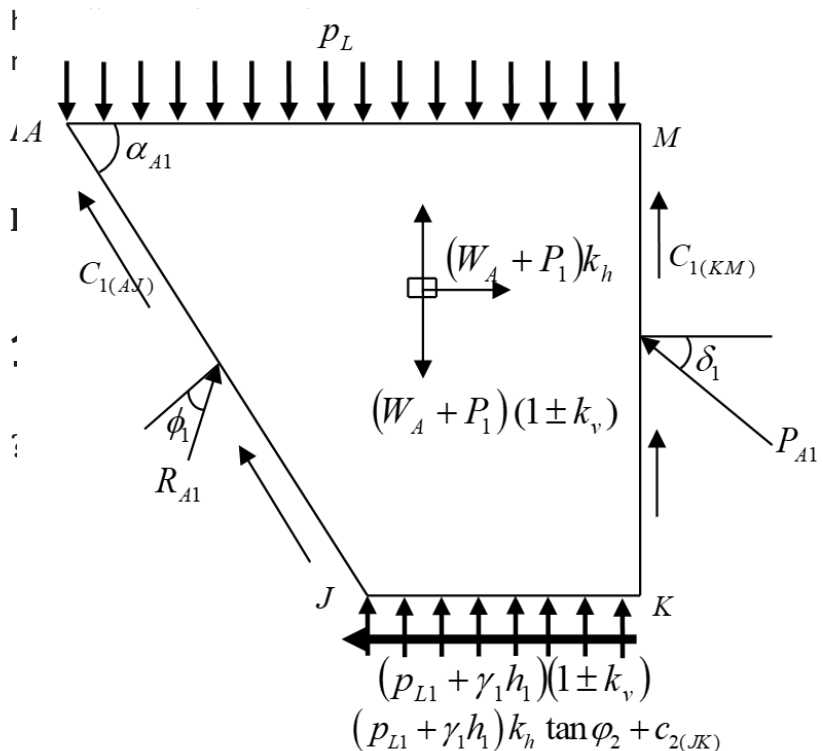

Figure 3: Active wedge in Top layer.

$$
P_{1}=p_{L} B_{0}
$$

Total cohesive force $\left(\mathrm{C}_{1}\right)$ on the slip lines $\mathrm{AJ}$ and $\mathrm{MK}$ is calculated as

$$
\begin{aligned}
& C_{1(M K)}=c_{1} h_{1}, C_{1(A J)}=c_{1} A J=c_{1} h_{1} \operatorname{cosec} \alpha_{A 1} \\
& C_{2(J K)}=c_{2} J K=c_{2}\left(B_{0}-h_{1} \cot \alpha_{A 1}\right)
\end{aligned}
$$

The intensity of load at layer thickness $h_{1}$ is expressed as (depicted in Fig. 7)

$$
p_{L 1}=\frac{p_{L} B_{0}}{\left(B_{0}+h_{1}\right)}
$$

Conceding to limit equilibrium conditions, the authors can write

$$
\begin{aligned}
& \sum V=0 \\
& \Rightarrow C_{1(A J)} \sin \alpha_{A 1}+C_{1(M K)}+R_{A 1} \cos \left(\alpha_{A 1}-\phi_{1}\right)+ \\
& +P_{A 1} \sin \delta_{1}+\left(p_{L 1}+\gamma_{1} h_{1}\right) J K\left(1-k_{V}\right)- \\
& -\left(P_{1}+W_{A}\right)\left(1-k_{V}\right)=0
\end{aligned}
$$

$\sum H=0$

$\Rightarrow-C_{1(A J)} \cos \alpha_{A 1}+R_{A 1} \sin \left(\alpha_{A 1}-\phi_{1}\right)-P_{A 1} \cos \left(\delta_{1}\right)-$

$-\left\{\left(p_{L 1}+\gamma_{1} h_{1}\right) J K k_{h} \tan \phi_{2}+c_{2(J K)} J K\right\}+$

$+\left(P_{1}+W_{A}\right) k_{h}=0$
After solving Equations 5 and 6 and modifying both,the active pressure can be obtained as given below:

$$
\begin{aligned}
& P_{A 1}=p_{L} B_{0}\left\{\frac{\left(1-k_{V}\right) \sin \left(\alpha_{A 1}-\phi_{1}\right)+k_{h} \cos \left(\alpha_{A 1}-\phi_{1}\right)}{\cos \left(\alpha_{A 1}-\phi_{1}-\delta_{1}\right)}\right\} \\
& -\left\{\frac{p_{L} B_{0}}{\left(B_{0}+h_{1}\right)}\left(B_{0}-h_{1} \cot \alpha_{A 1}\right)\right\} \\
& \left\{\frac{\left(1-k_{v}\right) \sin \left(\alpha_{A 1}-\phi_{1}\right)+k_{h} \tan \phi_{2} \cos \left(\alpha_{A 1}-\phi_{1}\right)}{\cos \left(\alpha_{A 1}-\phi_{1}-\delta_{1}\right)}\right\}+ \\
& \left.+\frac{2 B_{0}-h_{1} \cot \alpha_{A 1} h_{1} \gamma_{1}}{2}\right\}- \\
& \left\{\frac{\left(1-k_{V}\right) \sin \left(\alpha_{A 1}-\phi_{1}\right)+k_{h} \cos \left(\alpha_{A 1}-\phi_{1}\right)}{\cos \left(\alpha_{A 1}-\phi_{1}-\delta_{1}\right)}\right\}- \\
& \left\{\frac{\left(1-k_{v}\right) \sin \left(\alpha_{A 1}-\phi_{1}\right)+k_{h} \tan \phi_{2} \cos \left(\alpha_{A 1}-\phi_{1}\right)}{\cos \left(\alpha_{A 1}-\phi_{1}-\delta_{1}\right)}\right\}- \\
& -2 c_{1} h_{1} \frac{\sin \left(\alpha_{A 1}-\phi_{1}\right)}{\cos \left(\alpha_{A 1}-\phi_{1}-\delta_{1}\right)}-c_{2} B_{0} \frac{\cos \left(\alpha_{A 1}-\phi_{1}\right)}{\cos \left(\alpha_{A 1}-\phi_{1}-\delta_{1}\right)} \\
& -c_{1} h_{1} \cot \alpha_{A 1} \frac{\cos \left(\alpha_{A 1}-\phi_{1}\right)}{\cos \left(\alpha_{A 1}-\phi_{1}-\delta_{1}\right)}+ \\
& +c_{2} h_{1} \cot \alpha_{A 1} \frac{\cos \left(\alpha_{A 1}-\phi_{1}\right)}{\cos \left(\alpha_{A 1}-\phi_{1}-\delta_{1}\right)}
\end{aligned}
$$

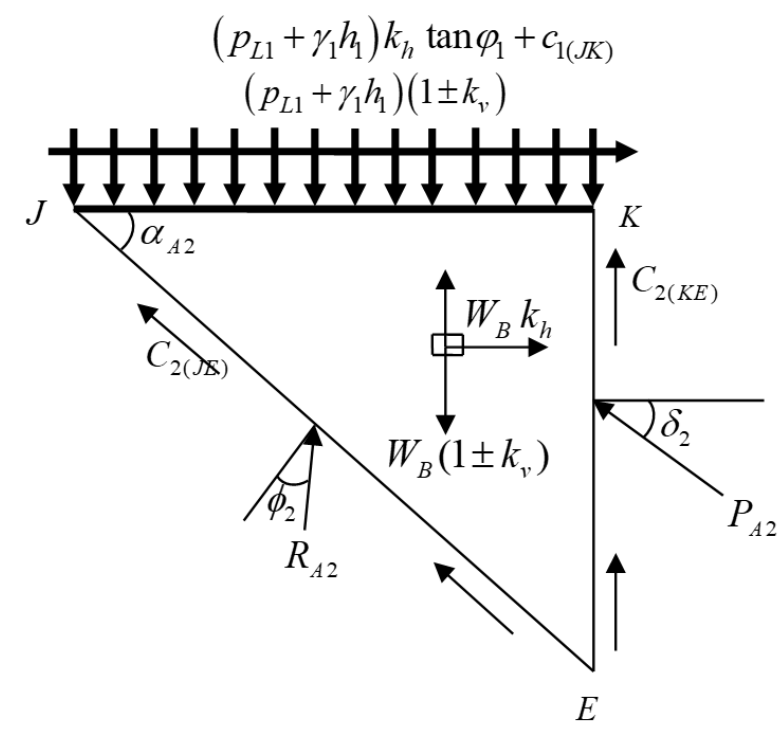

Figure 4: Active wedge in Bottom layer.

\subsection{Active pressure at the bottom layer}

From Fig. 4, active pressure distributing from the top layer tothe wedge $J K E$. 
The weight of the wedge:

$$
W_{B}=\frac{1}{2}\left(B_{0}-h_{1} \cot \alpha_{A 1}\right) h_{2} \gamma_{2}
$$

Base shear at the interface between the two layers is given as:

$$
\left(p_{L 1}+\gamma_{1} h_{1}\right) k_{h} \tan \varphi_{2}+c_{2}
$$

and

$$
\left(p_{L 1}+\gamma_{1} h_{1}\right) k_{h} \tan \varphi_{1}+c_{1}
$$

Total cohesive force at the slip lines JE and KE is expressed as:

$$
\begin{aligned}
& C_{2(K E)}=c_{2} K E=c_{2} h_{2}, \\
& C_{2(J E)}=c_{2} J E=c_{2} h_{2} \cos e c \alpha_{A 2} \\
& \text { and } \\
& C_{1(J K)}=c_{1} J K=c_{1}\left(B_{0}-h_{1} \cot \alpha_{A 1}\right)
\end{aligned}
$$

Conceding to limit equilibrium conditions,

$$
\begin{aligned}
& \sum V=0 \\
& \Rightarrow C_{2(J E)} \sin \alpha_{A 2}+C_{2(K E)^{+}} \\
& +R_{A 2} \cos \left(\alpha_{A 2}-\phi_{2}\right)+P_{A 2} \sin \delta_{2}- \\
& -\left(p_{L 1}+\gamma_{1} h_{1}\right) J K\left(1-k_{V}\right)-W_{B}\left(1-k_{v}\right)=0 \\
& \quad \sum H=0 \\
& \quad \Rightarrow C_{1(J K)}-C_{2(J E)} \cos \alpha_{A 2}+ \\
& +R_{A 2} \sin \left(\alpha_{A 2}-\phi_{2}\right)-P_{A 2} \cos \delta_{2}+ \\
& +\left(p_{L 1}+\gamma_{1} h_{1}\right) J K k_{h} \tan \phi_{1}+W_{B} k_{h}=0
\end{aligned}
$$

Solving Equations 11 and 12 and simplifying them, we obtain

$$
P_{A 2}=f_{1}\left(p_{L 1}, c_{2}, \phi_{2}, \gamma_{2}, \alpha_{A 2}\right)
$$

The details of equations of $P_{A 2}$ are given in Appendix I.

Hence, total active pressure from both the layers is given by

$$
P_{A}=P_{A 1}+P_{A 2}
$$

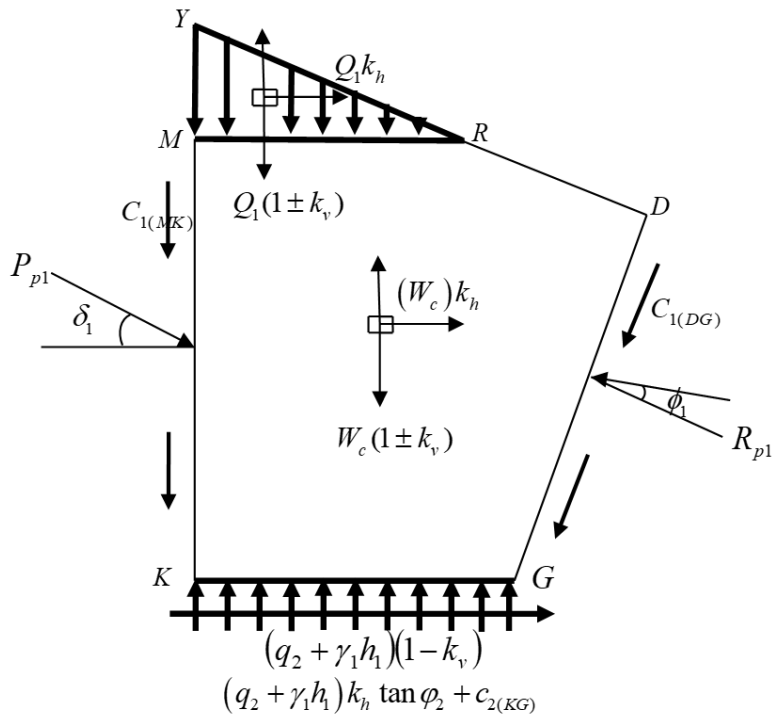

Figure 5: Passive wedge in Top layer.

\subsection{Passive resistance at the top layer}

Due to active pressure generated in the top layer, the passive zone gives resistance to the active pressure. The weight of the passive wedge, as depicted in Fig. 5, is given as

$$
\begin{aligned}
& W_{c}=\left[\frac{h_{1} \cot \alpha_{p 1}+2 h_{2} \cot \alpha_{p 2}}{2} h_{1-}\right. \\
& \left.-\frac{1}{4}\left(h_{1} \cot \alpha_{p 1}+h_{2} \cot \alpha_{p 2}-\frac{D_{f}}{\tan i}+\frac{B_{0}}{2}\right)^{2} \tan \alpha_{p 1}\right] \gamma_{1}
\end{aligned}
$$

Extra loadingacting on the foundation is expressed as surcharge load

$$
\begin{aligned}
q_{1} & =\gamma_{1}(Y M / 2) \\
& =\gamma_{1} \frac{1}{2} \tan i\left(\frac{D_{f}}{\tan i}-\frac{B_{0}}{2}\right)
\end{aligned}
$$

Total surcharge load in the top layer of the passive zone is given as

$$
\begin{aligned}
Q_{1} & =q_{1} M R \\
& =\frac{\gamma_{1}}{2} \tan i\left(\frac{D_{f}}{\tan i}-\frac{B_{0}}{2}\right)^{2}
\end{aligned}
$$

Total cohesive force in the slip lines KG and GD of the passive wedge is given as

$$
\begin{aligned}
& C_{1(K G)}=c_{1} K G=c_{1} h_{2} \cot \alpha_{p 2}, C_{1(M K)}=c_{1} M K=c_{1} h_{1} \\
& C_{1(G D)}=c_{1} G D=c_{1} h_{1} \cos e c \alpha_{p 1}- \\
& -c_{1}\left\{\frac{1}{2}\left(h_{1} \cot \alpha_{p 1}+h_{2} \cot \alpha_{p 2}-\frac{D_{f}}{\tan i}+\frac{B_{0}}{2}\right) \sec \alpha_{p 1}\right\}
\end{aligned}
$$


Using limit equilibrium equations

$$
\begin{aligned}
& \sum V=0 \\
& \Rightarrow-C_{1(M K)}-C_{1(G D)} \sin \alpha_{p 1^{+}} \\
& +R_{p 1} \cos \left(\phi_{1}+\alpha_{p 1}\right)-P_{p 1} \sin \delta_{1}+ \\
& +\left(q_{2}+\gamma_{1} h_{1}\right) K G\left(1-k_{v}\right)- \\
& -\left(Q_{1}+W_{c}\right)\left(1-k_{v}\right)=0 \\
& \sum H=0 \\
& \Rightarrow-C_{1(G D)} \cos \alpha_{p 1}+C_{1(G K)^{-}} \\
& -R_{p 1} \sin \left(\phi_{1}+\alpha_{p 1}\right)+P_{p 1} \cos \delta_{1}+ \\
& +\left(q_{2}+\gamma_{1} h_{1}\right) K G k_{h} \tan \phi_{2}+ \\
& +\left(Q_{1}+W_{c}\right) k_{h}=0
\end{aligned}
$$

Solving Equations 19 and 20 and modifying both equations, passive resistance can be expressed as:

$P_{p 1}=\left[\frac{h_{1} \cot \alpha_{p 1}+h_{2} \cot \alpha_{p 2}}{2} h_{1-}\right.$

$-\frac{1}{4}\left(h_{1} \cot \alpha_{p 1}+h_{2} \cot \alpha_{p 2}-\frac{D_{f}}{\tan i}+\frac{B_{0}}{2}\right)^{2} \tan \alpha_{p 1} 1 \gamma_{1}$

$\left\{\frac{\left(1-k_{v}\right) \sin \left(\phi_{1}+\alpha_{p 1}\right)-k_{h} \cos \left(\phi_{1}+\alpha_{p 1}\right)}{\cos \left(\phi_{1}+\alpha_{p 1}+\delta_{1}\right)}\right\}$

$-\gamma_{1} h_{1} h_{2} \cot \alpha_{p 2}\left\{\frac{\left(1-k_{v}\right) \sin \left(\phi_{1}+\alpha_{p 1}\right)+k_{h} \tan \phi_{2} \cos \left(\phi_{1}+\alpha_{p_{1}}\right)}{\cos \left(\phi_{1}+\alpha_{p 1}+\delta_{1}\right)}\right\}$

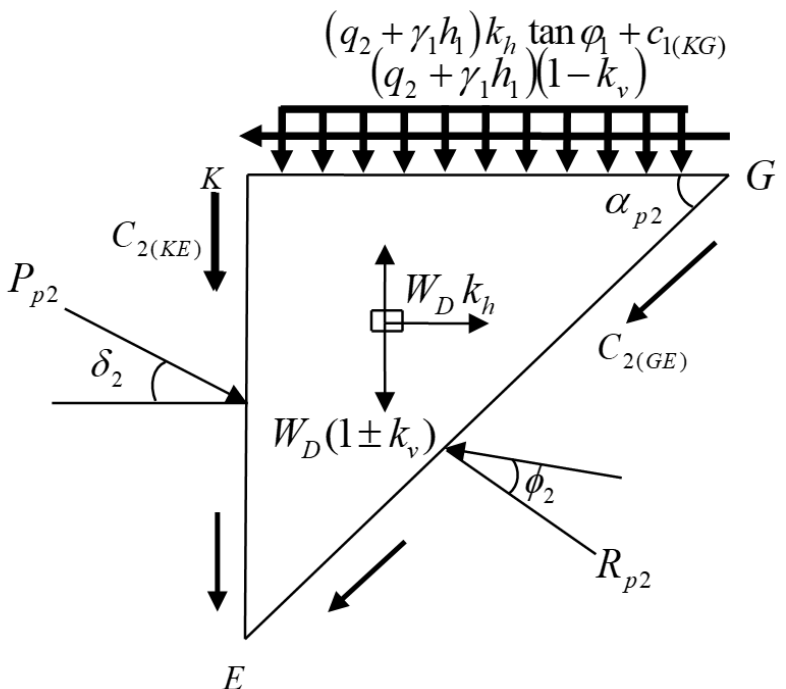

Figure 6: Passive wedge in Bottom layer.

$$
-\gamma_{1} \frac{\tan \left(\frac{D_{f}}{\tan i}-\frac{B_{0}}{2}\right)\left(2 D_{f}-B_{0} \tan i\right)}{2 D_{f}+\tan i\left(2 h_{1}-B_{0}\right)} h_{2} \cot \alpha_{p 2}
$$

$\left\{\frac{\left(1-k_{v}\right) \sin \left(\phi_{1}+\alpha_{p 1}\right)+k_{h} \tan \phi_{2} \cos \left(\phi_{1}+\alpha_{p 1}\right)}{\cos \left(\phi_{1}+\alpha_{p 1}+\delta_{1}\right)}\right\}$

$$
W_{D}=\frac{1}{2} h_{2}{ }^{2} \cot \alpha_{p 2} \gamma_{2}
$$

$+\gamma_{1} \tan i\left(\frac{D_{f}}{\tan i}-\frac{B_{0}}{2}\right)^{2}\left\{\frac{\left(1-k_{\nu}\right) \sin \left(\phi_{1}+\alpha_{p 1}\right)-k_{h} \cos \left(\phi_{1}+\alpha_{p 1}\right)}{\cos \left(\phi_{1}+\alpha_{p 1}+\delta_{1}\right)}\right\}+$

$c_{1} h_{1}\left\{\frac{\sin \left(\phi_{1}+\alpha_{p 1}\right)}{\cos \left(\phi_{1}+\alpha_{p 1}+\delta_{1}\right)}\right\}$

According to $2: 1$ load distribution method, intensity $+c_{1} \sin \alpha_{p 1}\left[\frac{h_{1}}{2} \operatorname{cosec} \alpha_{p 1}-\frac{h_{2}}{2} \cot \alpha_{p 2} \sec \alpha_{p 1}+\frac{1}{2} \frac{D_{f}}{\tan i} \sec \alpha_{p 1}-\frac{B_{0}}{4} \sec \alpha_{p 1}\right]$

$\left\{\frac{\sin \left(\phi_{1}+\alpha_{p 1}\right)}{\cos \left(\phi_{1}+\alpha_{p 1}+\delta_{1}\right)}\right\}$

$+c_{1} \cos \alpha_{p 1}\left[\frac{h_{1}}{2} \operatorname{cosec} \alpha_{p 1}-\frac{h_{2}}{2} \cot \alpha_{p 2} \sec \alpha_{p 1}+\frac{1}{2} \frac{D_{f}}{\tan i} \sec \alpha_{p 1}-\frac{B_{0}}{4} \sec \alpha_{p 1}\right]$

$$
p_{L 1}=\frac{p_{L} B_{0}}{\left(B_{0}+h_{1}\right)}
$$

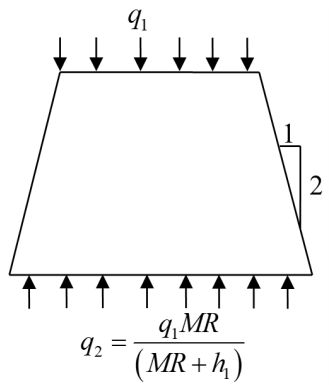

Figure 7: Load spread mechanism.

$\frac{\cos \left(\phi_{1}+\alpha_{p 1}\right)}{\cos \left(\phi_{1}+\alpha_{p 1}+\delta_{1}\right)}-c_{1} h_{2} \cot \alpha_{p 2} \frac{\cos \left(\phi_{1}+\alpha_{p 1}\right)}{\cos \left(\phi_{1}+\alpha_{p 1}+\delta_{1}\right)}$

Base shear between two passive wedges can be coded

\subsection{Passive resistance at the bottom layer}

Total weight of the passive wedge KGE, as shownin Fig. 6, is calculated as

$$
\begin{aligned}
q_{2} & =\frac{q_{1} M R}{\left(M R+h_{1}\right)} \\
& =\frac{\frac{\gamma_{1}}{2} \tan i\left(\frac{D}{\tan i}-\frac{B_{0}}{2}\right)^{2}}{\left(\frac{D_{f}}{\tan i}-\frac{B_{0}}{2}\right)+h_{1}}
\end{aligned}
$$

$\left(q_{2}+\gamma_{1} h_{1}\right) k_{h} \tan \varphi_{2}+c_{1}$ and $\left(q_{2}+\gamma_{1} h_{1}\right) k_{h} \tan \varphi_{1}+c_{1}$

Cohesive forces in slip lines KE, KG and GE are given 
Case 1: Considering the effective area of active zones

$$
\begin{gathered}
\bar{\gamma}=\frac{\frac{\left(2-\frac{h_{1}}{B_{0}} \cot \alpha_{A 1}\right)}{2} h_{1} \gamma_{1}+\frac{\left(1-\frac{h_{1}}{B_{0}} \cot \alpha_{A 1}\right)}{2} h_{2} \gamma_{2}}{\frac{\left(2-\frac{h_{1}}{B_{0}} \cot \alpha_{A 1}\right)}{2} h_{1}+\frac{\left(1-\frac{h_{1}}{B_{0}} \cot \alpha_{A 1}\right)}{2} h_{2}} \\
\bar{\gamma}=\frac{\left\{\left(\frac{h_{1}}{B_{0}} \cot \alpha_{p 1}+2 \frac{h_{2}}{B_{0}} \cot \alpha_{p 2}\right) \frac{h_{1}}{2 B_{0}}-\frac{1}{4}\left(\frac{h_{1}}{B_{0}} \cot \alpha_{p 1}+\frac{h_{2}}{B_{0}} \cot \alpha_{p 2}-\frac{D_{f}}{B_{0} \tan i}+\frac{1}{2}\right)^{2} \tan \alpha_{1}\right\} \gamma_{1}+\frac{1}{2}\left(\frac{h_{2}}{B_{0}}\right)^{2} \cot \alpha_{p 2} \gamma_{2}}{\left\{\left(\frac{h_{1}}{B_{0}} \cot \alpha_{p_{1}}+2 \frac{h_{2}}{B_{0}} \cot \alpha_{p 2}\right) \frac{h_{1}}{2 B_{0}}-\frac{1}{4}\left(\frac{h_{1}}{B_{0}} \cot \alpha_{p 1}+\frac{h_{2}}{B_{0}} \cot \alpha_{p 2}-\frac{D_{f}}{B_{0} \tan i}+\frac{1}{2}\right)^{2} \tan \alpha_{1}\right\}+\frac{1}{2}\left(\frac{h_{2}}{B_{0}}\right)^{2} \cot \alpha_{p 2}}
\end{gathered}
$$

The bearing capacity factor $\left(N_{\gamma^{\prime}}\right)$ is a function of several parameters including cohesion, surcharge and unit weight. It can be expressed as:

$$
N_{\gamma^{\prime \prime}}=\left(\frac{a_{1}}{e_{1}}+\frac{b_{1}}{e_{1}}+\frac{2 \bar{c}}{\bar{\gamma} B_{0}} \frac{d_{1}}{e_{1}}\right)
$$

The details of the equations $\mathrm{a}_{1}, \mathrm{~b}_{1}, \mathrm{e}_{1}$ and $\mathrm{d}_{1}$ are given in Appendix II.

Where $\bar{c}$ is averaged cohesion in each layer in the slip line is shown by

$$
\bar{c}=\frac{c_{1} h_{1}+c_{2} h_{2}}{h_{1}+h_{2}}
$$

$\mathrm{a}_{1}, \mathrm{~b}_{1}, \mathrm{e}_{1}$ and $\mathrm{d}_{1}$ are dimensionless equations.

In seismic condition, $\left(N_{\gamma^{\prime \prime}}\right)$ can be expressed as $\left(N_{\gamma E}\right)$ and in static condition, $\left(N_{\gamma^{\prime \prime}}\right)$ can be expressed as $\left(N_{\gamma S}\right)$, whereas $\left(N_{\gamma^{\prime \prime}}\right)$ is the unity factor for the simultaneous resistance of unit weight, surcharge and cohesion.

\section{Results and Discussion}

The bearing capacity factor $\left(N_{\gamma^{\prime \prime}}\right)$ has been computed by PSO algorithm, with the optimum $\left(N_{\gamma^{\prime \prime}}\right)$ optimized w.r.t. variables $\alpha_{A 1}, \alpha_{A 2}, \alpha_{p 1}$ and $\alpha_{p 2}$. The minimum value is taken as an optimised value. The design charts of the obtained bearing capacity coefficients $\left(N_{\gamma^{\prime \prime}}\right)$ for different values of slope angle (i) are shown in Figs 8 and 9 $\left(\phi=30^{\circ}, 40^{\circ}, \frac{D_{f}}{B_{0}}=1\right)$. It has been observed that $\left(N_{\gamma^{\prime \prime}}\right)$ decreases when the slope angle (i) increases. The results obtained from MATLAB are summarised in design Tables 1 and 2. Using these design tables, the bearing capacity coefficients of the strip footing near slope are easily obtained with sufficient accuracy from the engineering point of view.Undrained bearing capacity is expressed as $N_{c s}$ in the design tables.

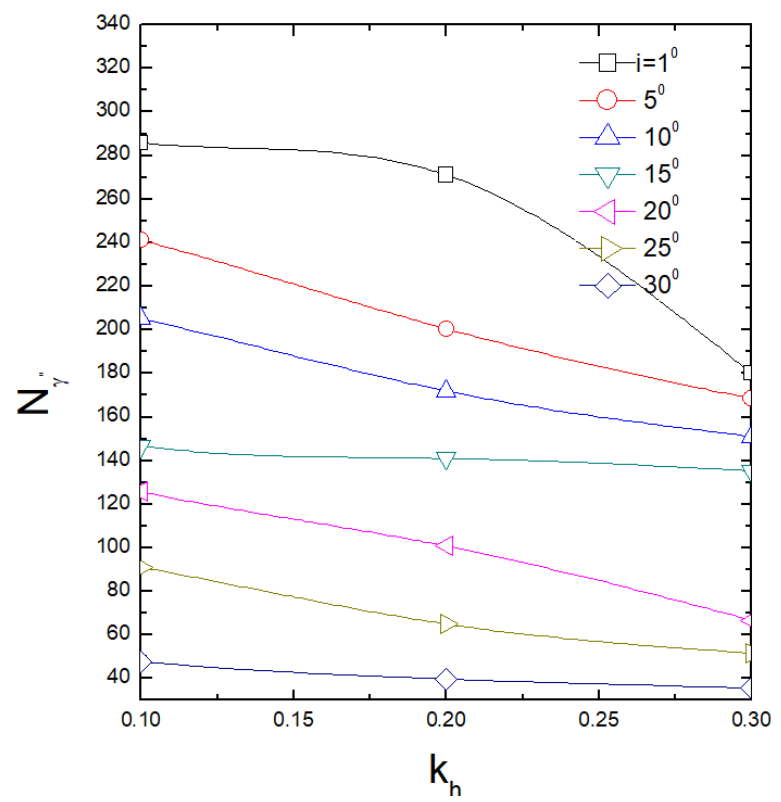

Figure 8: Design chart of Bearing capacity coefficient at $\phi_{2}=$ $30^{\circ}, \delta_{2}=\phi_{2} / 2, i=15^{0}, \delta_{1} / \delta_{2}=0.8, \mathrm{k}_{\mathrm{v}}=\mathrm{k}_{\mathrm{h}} / 2, \gamma_{1} / \gamma_{2}=$ $0.8, \mathrm{D}_{\mathrm{f}} / \mathrm{B}_{0}=0.5, \mathrm{~h}_{1} / \mathrm{B}_{0}=0.25,2 \mathrm{c}_{2} / \mathrm{B}_{0} \gamma_{2}=0.2, \mathrm{c}_{1} / \mathrm{c}_{2}=0.8$.

\subsection{Computation of $N_{c s}$}

Merifield et al. (1999) investigated the bearing capacity of a strip footing resting on a two-layer clay deposit with a horizontal ground surface and proposed a modified bearing capacity factor $N_{c}{ }^{*}$, which can be expressed as:

$$
N_{c}{ }^{*}=\frac{q_{u}}{c_{1}}
$$

where $q_{u}=$ ultimate bearing capacity and $c_{1}=$ undrained shear strength of the top layer.

Similarly, a dimensionless undrained bearing capacity factor $N_{C S}$ is defined in the present study, which is a function of the parameters $c_{u} / \gamma B_{0}, D_{f} / B_{0}, c_{1} / c_{2}, i, k_{h}$ and it can be described by the following equation:

$$
N_{c s}=q_{u l t} / c_{1}=f\left(c_{u} / \gamma B_{0}, D_{f} / B_{0}, c_{1} / c_{2}, i, k_{h}\right)
$$


Table 1: Undrained seismic bearing capacity $\mathrm{N}_{\mathrm{cs}}$ for strip footing placed adjacent to two layered slope with $\mathrm{i}=15^{\circ}$.

\begin{tabular}{|c|c|c|c|c|c|c|c|c|c|c|c|c|c|}
\hline \multirow{2}{*}{$\mathrm{k}_{\mathrm{h}}$} & \multirow{2}{*}{$D_{f} / B_{0}$} & \multirow{2}{*}{$c_{1} / c_{2}$} & \multicolumn{4}{|c|}{$\mathrm{c}_{1} / \gamma \mathrm{B}_{0}$} & \multirow{2}{*}{$\mathrm{k}_{\mathrm{h}}$} & \multirow{2}{*}{$D_{f} / B_{0}$} & \multirow{2}{*}{$c_{1} / c_{2}$} & \multicolumn{4}{|c|}{$\mathrm{C}_{1} / \gamma \mathrm{B}_{0}$} \\
\hline & & & 1 & 2 & 4 & 6 & & & & 1 & 2 & 4 & 6 \\
\hline & & 0.25 & 5.52 & 5.54 & 5.56 & 5.56 & & & 0.25 & 4.54 & 4.60 & 4.62 & 4.64 \\
\hline & & 0.5 & 5.52 & 5.54 & 5.56 & 5.56 & & & 0.5 & 4.52 & 4.60 & 4.61 & 4.63 \\
\hline & & 0.75 & 5.42 & 5.37 & 5.43 & 5.46 & & & 0.75 & 4.52 & 4.60 & 4.60 & 4.62 \\
\hline & & 1 & 4.74 & 4.40 & 4.41 & 4.42 & & & 1 & 4.36 & 4.42 & 4.44 & 4.47 \\
\hline & 0.25 & 1.5 & 3.05 & 3.17 & 3.22 & 3.22 & & 0.50 & 1.5 & 3.32 & 3.45 & 3.52 & 3.54 \\
\hline & & 2 & 2.4 & 2.52 & 2.58 & 2.6 & & & 2 & 1.55 & 2.82 & 2.90 & 2.92 \\
\hline & & 3 & - & 1.80 & 1.85 & 1.88 & & & 3 & - & 2.12 & 2.22 & 2.24 \\
\hline & & 4 & - & 0.6 & 1.51 & 1.53 & & & 4 & - & 0.91 & 1.84 & 1.90 \\
\hline & & 5 & - & - & 1.29 & 1.31 & & & 5 & - & - & 1.61 & 1.64 \\
\hline & & 0.25 & 4.50 & 4.46 & 4.25 & 4.49 & & & 0.25 & 4.40 & 4.49 & 4.52 & 4.53 \\
\hline & & 0.5 & 4.5 & 4.48 & 4.53 & 4.59 & & & 0.5 & 4.39 & 4.49 & 4.52 & 4.53 \\
\hline & & 0.75 & 4.4 & 4.4 & 4.54 & 4.58 & & & 0.75 & 4.38 & 4.49 & 4.52 & 4.53 \\
\hline & & 1 & 4.35 & 4.2 & 4.45 & 4.49 & & & 1 & 4.38 & 4.44 & 4.47 & 4.48 \\
\hline \multirow[t]{27}{*}{0} & 0.75 & 1.5 & 4.05 & 3.84 & 3.93 & 3.96 & 0 & 1 & 1.5 & 3.88 & 4.2 & 4.3 & 4.33 \\
\hline & & 2 & 3.45 & 3.24 & 3.36 & 3.4 & & & 2 & 1.87 & 3.62 & 3.76 & 3.82 \\
\hline & & 3 & - & 2.44 & 2.62 & 2.68 & & & 3 & - & 2.7 & 3.07 & 3.13 \\
\hline & & 4 & - & 1.12 & 2.20 & 2.28 & & & 4 & - & 1.38 & 2.64 & 2.71 \\
\hline & & 5 & - & - & 1.92 & 2.0 & & & 5 & - & - & 2.27 & 2.42 \\
\hline & & 0.25 & 4.42 & 4.46 & 4.50 & 4.52 & & & 0.25 & 4.44 & 4.50 & 4.52 & 4.53 \\
\hline & & 0.5 & 4.41 & 4.43 & 4.48 & 4.51 & & & 0.5 & 4.41 & 4.49 & 4.52 & 4.53 \\
\hline & & 0.75 & 4.40 & 4.42 & 4.47 & 4.50 & & & 0.75 & 4.41 & 4.49 & 4.52 & 4.54 \\
\hline & & 1 & 4.39 & 4.41 & 4.45 & 4.48 & & & 1 & 4.38 & 4.44 & 4.47 & 4.48 \\
\hline & 1.25 & 1.5 & 4.01 & 3.59 & 3.74 & 3.85 & & 1.5 & 1.5 & 4.17 & 4.49 & 4.52 & 4.44 \\
\hline & & 2 & 3.67 & 3.2 & 3.42 & 3.45 & & & 2 & 2.34 & 4.18 & 4.31 & 4.37 \\
\hline & & 3 & - & 2.64 & 2.92 & 2.97 & & & 3 & - & 3.1 & 3.54 & 3.74 \\
\hline & & 4 & - & 1.67 & 2.59 & 2.67 & & & 4 & - & 1.92 & 3.3 & 3.43 \\
\hline & & 5 & - & - & 2.36 & 2.48 & & & 5 & - & - & 2.87 & 3.12 \\
\hline & & 0.25 & 4.84 & 4.79 & 4.8 & 4.81 & & & 0.25 & 4.12 & 4.2 & 4.23 & 4.24 \\
\hline & & 0.5 & 4.82 & 4.78 & 4.8 & 4.81 & & & 0.5 & 4.13 & 4.2 & 4.24 & 4.24 \\
\hline & & 0.75 & 4.64 & 4.79 & 4.8 & 4.81 & & & 0.75 & 4.13 & 4.2 & 4.24 & 4.24 \\
\hline & & 1 & 4.12 & 4.15 & 4.2 & 4.21 & & & 1 & 4.06 & 4.15 & 4.19 & 4.21 \\
\hline & 0.25 & 1.5 & - & 3.03 & 3.09 & 3.11 & & 0.5 & 1.5 & - & 3.37 & 3.46 & 3.5 \\
\hline & & 2 & - & 2.42 & 2.49 & 2.51 & & & 2 & - & 2.76 & 2.87 & 2.91 \\
\hline & & 3 & - & - & 1.82 & 1.87 & & & 3 & - & - & 2.21 & 2.25 \\
\hline & & 4 & - & - & 1.47 & 1.51 & & & 4 & - & - & 1.85 & 1.89 \\
\hline & & 5 & - & - & - & 1.28 & & & 5 & - & - & - & 1.65 \\
\hline & & 0.25 & 4.11 & 4.14 & 4.18 & 4.2 & & & 0.25 & 4.06 & 4.15 & 4.18 & 4.19 \\
\hline & & 0.5 & 4.08 & 4.13 & 4.18 & 4.19 & & & 0.5 & 4.05 & 4.14 & 4.19 & 4.19 \\
\hline & & 0.75 & 4.06 & 4.14 & 4.18 & 4.19 & & & 0.75 & 4.04 & 4.13 & 4.18 & 4.19 \\
\hline & & 1 & 4.04 & 4.15 & 4.2 & 4.21 & & & 1 & 4.02 & 4.11 & 4.14 & 4.17 \\
\hline \multirow[t]{14}{*}{0.1} & 0.75 & 1.5 & - & 3.74 & 3.85 & 3.89 & 0.1 & 1 & 1.5 & - & 4.07 & 4.18 & 4.2 \\
\hline & & 2 & - & 3.13 & 3.31 & 3.36 & & & 2 & - & 3.48 & 3.71 & 3.79 \\
\hline & & 3 & - & - & 2.61 & 2.68 & & & 3 & - & - & 3.01 & 3.1 \\
\hline & & 4 & - & - & 2.14 & 2.28 & & & 4 & - & - & 2.34 & 2.67 \\
\hline & & 5 & - & - & - & 2.02 & & & 5 & - & - & - & 2.38 \\
\hline & & 0.25 & 4.08 & 4.14 & 4.18 & 4.19 & & & 0.25 & 4.05 & 4.14 & 4.18 & 4.19 \\
\hline & & 0.5 & 4.06 & 4.14 & 4.18 & 4.2 & & & 0.5 & 4.04 & 4.14 & 4.18 & 4.19 \\
\hline & & 0.75 & 4.05 & 4.13 & 4.18 & 4.19 & & & 0.75 & 4.05 & 4.14 & 4.18 & 4.19 \\
\hline & & 1 & 4.04 & 4.15 & 4.2 & 4.21 & & & 1 & 4.06 & 4.14 & 4.19 & 4.2 \\
\hline & 1.25 & 1.5 & - & 4.14 & 4.19 & 4.2 & & 1.5 & 1.5 & - & 4.14 & 4.19 & 4.2 \\
\hline & & 2 & - & 3.84 & 4.07 & 4.16 & & & 2 & - & 3.95 & 4.18 & 4.2 \\
\hline & & 3 & - & - & 3.37 & 3.48 & & & 3 & - & - & 3.67 & 3.82 \\
\hline & & 4 & - & - & 2.54 & 3.05 & & & 4 & - & - & 2.72 & 3.38 \\
\hline & & 5 & - & - & - & 2.68 & & & 5 & - & - & - & 2.98 \\
\hline
\end{tabular}


Table 2: Undrained seismic bearing capacity $\mathrm{N}_{\mathrm{cs}}$ for strip footing placed adjacent to two layered slope with $\mathrm{i}=30^{\circ}$.

\begin{tabular}{|c|c|c|c|c|c|c|c|c|c|c|c|c|c|}
\hline \multirow{2}{*}{$k_{h}$} & \multirow{2}{*}{$D_{f} / B_{0}$} & \multirow{2}{*}{$\mathrm{c}_{1} / \mathrm{c}_{2}$} & \multicolumn{4}{|c|}{$\mathrm{c}_{1} / \gamma \mathrm{B}_{0}$} & \multirow{2}{*}{$\mathrm{k}_{\mathrm{h}}$} & \multirow{2}{*}{$\mathrm{D}_{\mathrm{f}} / \mathrm{B}_{0}$} & \multirow{2}{*}{$c_{1} / c_{2}$} & \multicolumn{4}{|c|}{$\mathrm{c}_{1} / \gamma \mathrm{B}_{0}$} \\
\hline & & & 1 & 2 & 4 & 6 & & & & 1 & 2 & 4 & 6 \\
\hline & & 0.25 & 5.12 & 5.16 & 5.18 & 5.19 & & & 0.25 & 4.06 & 4.14 & 4.21 & 4.23 \\
\hline & & 0.5 & 5.12 & 5.16 & 5.18 & 5.19 & & & 0.5 & 4.05 & 4.13 & 4.19 & 4.22 \\
\hline & & 0.75 & 4.82 & 4.91 & 4.96 & 4.97 & & & 0.75 & 4.03 & 4.11 & 4.17 & 4.20 \\
\hline & & 1 & 3.8 & 3.96 & 4.03 & 4.05 & & & 1 & 3.8 & 3.96 & 4.06 & 4.08 \\
\hline & 0.25 & 1.5 & 2.23 & 2.81 & 2.9 & 2.93 & & 0.5 & 1.5 & 2.32 & 3.01 & 3.10 & 3.12 \\
\hline & & 2 & - & 2.18 & 2.3 & 2.33 & & & 2 & - & 2.45 & 2.61 & 2.65 \\
\hline & & 3 & - & 1.25 & 1.68 & 1.72 & & & 3 & - & 1.44 & 2 & 2.06 \\
\hline & & 4 & - & - & 1.33 & 1.38 & & & 4 & - & - & 1.65 & 1.72 \\
\hline & & 5 & - & - & 1 & 1.17 & & & 5 & - & - & 1.24 & 1.5 \\
\hline & & 0.25 & 3.82 & 3.97 & 4.06 & 4.09 & & & 0.25 & 3.80 & 3.92 & 4.04 & 4.06 \\
\hline & & 0.5 & 3.83 & 3.97 & 4.06 & 4.09 & & & 0.5 & 3.80 & 3.92 & 4.04 & 4.06 \\
\hline & & 0.75 & 3.82 & 3.97 & 4.07 & 4.09 & & & 0.75 & 3.80 & 3.91 & 4.04 & 4.06 \\
\hline & & 1 & 3.8 & 3.96 & 4.06 & 4.09 & & & 1 & 3.82 & 3.96 & 4.03 & 4.05 \\
\hline \multirow[t]{27}{*}{0} & 0.75 & 1.5 & 2.51 & 3.25 & 3.37 & 3.41 & 0 & 1 & 1.5 & 2.64 & 3.44 & 3.59 & 3.64 \\
\hline & & 2 & - & 2.73 & 2.9 & 2.95 & & & 2 & - & 2.96 & 3.17 & 3.23 \\
\hline & & 3 & - & 1.67 & 2.31 & 2.38 & & & 3 & - & 1.86 & 2.56 & 2.67 \\
\hline & & 4 & - & - & 1.92 & 2.05 & & & 4 & - & - & 2.17 & 2.34 \\
\hline & & 5 & - & - & 1.5 & 1.8 & & & 5 & - & - & 1.74 & 2.07 \\
\hline & & 0.25 & 3.83 & 3.96 & 4.03 & 4.06 & & & 0.25 & 3.8 & 3.96 & 4.03 & 4.05 \\
\hline & & 0.5 & 3.83 & 3.96 & 4.03 & 4.05 & & & 0.5 & 3.79 & 3.96 & 4.02 & 4.04 \\
\hline & & 0.75 & 3.83 & 3.96 & 4.03 & 4.05 & & & 0.75 & 3.8 & 3.96 & 4.03 & 4.05 \\
\hline & & 1 & 3.83 & 3.96 & 4.03 & 4.05 & & & 1 & 3.8 & 3.96 & 4.03 & 4.05 \\
\hline & 1.25 & 1.5 & 2.74 & 3.65 & 3.84 & 3.9 & & 1.5 & 1.5 & 2.8 & 3.84 & 4.01 & 4.04 \\
\hline & & 2 & - & 3.2 & 3.45 & 3.53 & & & 2 & - & 3.41 & 3.71 & 3.8 \\
\hline & & 3 & - & 2.1 & 2.9 & 3.02 & & & 3 & - & 2.33 & 3.18 & 3.32 \\
\hline & & 4 & - & - & 2.43 & 2.64 & & & 4 & - & - & 2.69 & 2.94 \\
\hline & & 5 & - & - & 2.02 & 2.35 & & & 5 & - & - & 2.28 & 2.64 \\
\hline & & 0.25 & 4.25 & 4.31 & 4.34 & 4.34 & & & 0.25 & 3.57 & 3.68 & 3.74 & 3.76 \\
\hline & & 0.5 & 4.25 & 4.31 & 4.34 & 4.35 & & & 0.5 & 3.57 & 3.69 & 3.74 & 3.76 \\
\hline & & 0.75 & 4.25 & 4.31 & 4.33 & 4.33 & & & 0.75 & 3.57 & 3.69 & 3.74 & 3.76 \\
\hline & & 1 & 3.44 & 3.6 & 3.67 & 3.7 & & & 1 & 3.44 & 3.61 & 3.68 & 3.71 \\
\hline & 0.25 & 1.5 & - & 2.6 & 2.7 & 2.73 & & 0.5 & 1.5 & - & 2.82 & 2.94 & 2.97 \\
\hline & & 2 & - & 2.03 & 2.15 & 2.19 & & & 2 & - & 2.29 & 2.46 & 2.5 \\
\hline & & 3 & - & - & 1.57 & 1.61 & & & 3 & - & - & 1.89 & 1.95 \\
\hline & & 4 & - & - & 1.23 & 1.3 & & & 4 & - & - & 1.48 & 1.64 \\
\hline & & 5 & - & - & - & 1.1 & & & 5 & - & - & - & 1.4 \\
\hline & & 0.25 & 3.45 & 3.61 & 3.68 & 3.7 & & & 0.25 & 3.44 & 3.61 & 3.68 & 3.7 \\
\hline & & 0.5 & 3.45 & 3.61 & 3.68 & 3.7 & & & 0.5 & 3.44 & 3.61 & 3.68 & 3.7 \\
\hline & & 0.75 & 3.45 & 3.61 & 3.68 & 3.7 & & & 0.75 & 3.45 & 3.61 & 3.68 & 3.71 \\
\hline & & 1 & 3.45 & 3.61 & 3.68 & 3.7 & & & 1 & 3.45 & 3.61 & 3.68 & 3.7 \\
\hline \multirow[t]{14}{*}{0.1} & 0.75 & 1.5 & - & 3.04 & 3.18 & 3.22 & 0.1 & 1 & 1.5 & - & 3.23 & 3.44 & 3.5 \\
\hline & & 2 & - & 2.55 & 2.75 & 2.81 & & & 2 & - & 2.78 & 3.04 & 3.12 \\
\hline & & 3 & - & - & 2.2 & 2.28 & & & 3 & - & - & 2.5 & 2.62 \\
\hline & & 4 & - & - & 1.74 & 1.96 & & & 4 & - & - & 2.03 & 2.27 \\
\hline & & 5 & - & - & - & 1.74 & & & 5 & - & - & - & 1.97 \\
\hline & & 0.25 & 3.45 & 3.61 & 3.68 & 3.67 & & & 0.25 & 3.44 & 3.61 & 3.68 & 3.7 \\
\hline & & 0.5 & 3.44 & 3.61 & 3.68 & 3.67 & & & 0.5 & 3.44 & 3.61 & 3.68 & 3.7 \\
\hline & & 0.75 & 3.44 & 3.61 & 3.68 & 3.67 & & & 0.75 & 3.44 & 3.61 & 3.68 & 3.7 \\
\hline & & 1 & 3.45 & 3.61 & 3.68 & 3.7 & & & 1 & 3.45 & 3.62 & 3.68 & 3.7 \\
\hline & 1.25 & 1.5 & - & 3.47 & 3.68 & 3.71 & & 1.5 & 1.5 & - & 3.61 & 3.68 & 3.7 \\
\hline & & 2 & - & 2.95 & 3.3 & 3.38 & & & 2 & - & 3.13 & 3.59 & 3.68 \\
\hline & & 3 & - & - & 2.76 & 2.91 & & & 3 & - & - & 3.06 & 3.24 \\
\hline & & 4 & - & - & 2.18 & 2.54 & & & 4 & - & - & 2.33 & 2.86 \\
\hline & & 5 & - & - & - & 2.22 & & & 5 & - & - & - & 2.53 \\
\hline
\end{tabular}




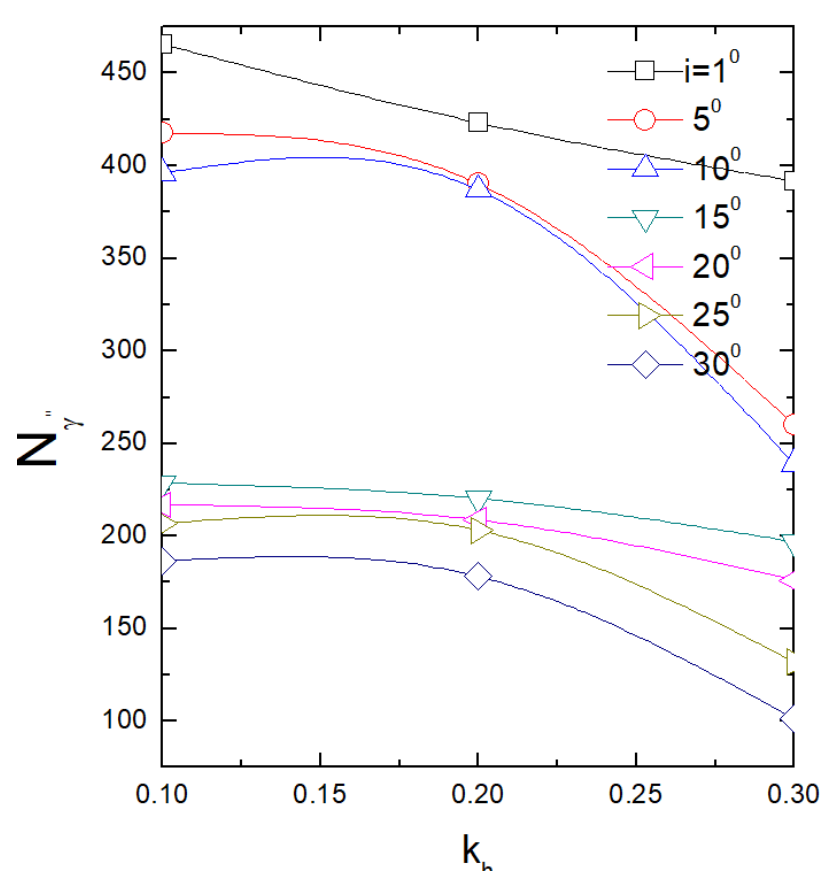

Figure 9: Design chart of Bearing capacity coefficient at $\phi_{2}=$ $40^{\circ}, \delta_{2}=\phi_{2} / 2, i=15^{\circ}, \delta_{1} / \delta_{2}=0.8, \mathrm{k}_{\mathrm{v}}=\mathrm{k}_{\mathrm{h}} / 2, \gamma_{1} / \gamma_{2}=$ $0.8, \mathrm{D}_{\mathrm{f}} / \mathrm{B}_{0}=1, \mathrm{~h}_{1} / \mathrm{B}_{0}=0.25,2 \mathrm{c}_{2} / \mathrm{B}_{0} \gamma_{2}=0.2, \mathrm{c}_{1} / \mathrm{c}_{2}=0.8$

Ranges of various parameters are given as follows: $\frac{\phi_{1}}{\phi_{2}}=0.6,0.8,1 \frac{\gamma_{1}}{\gamma_{2}}=0.6,0.8,1 \frac{h_{1}}{B_{0}}=0.1,0.25,0.5$

$$
i=10^{0}, 15^{0}, 20^{\circ}, 25^{\circ} k_{v}=0, k_{h} / 2, k_{h}
$$

$\frac{\delta_{1}}{\delta_{2}}$ is the ratio of wall friction angles between the top and bottom layers.

Since the heuristic algorithms give us low ramification and high execution and these methods are relatively new, they can be applied in the geotechnical problem. Out of these methods, a brief discussion on PSO is given here as it is used in the analysis.

\subsection{Particle swarm optimisation}

Kennedy and Eberhart (1995) developed PSO as a simulation of birds swarm. A swarm is a group of individuals with defined rules for individual behaviours and communication. The ability of each individual to deal with the previous experiences of the swarm is called swarm intelligence. This capability guides the swarm towards its optimum goal. PSO is a population-based search technique where a population of particles start their journey in a space concerning the current best position (Hossain and EI-Shafie 2014; Hajihassani et al.2017). Reynolds (1987) described three simple rules for the behaviours of individuals inside a swarm, which were used as one of the ba-

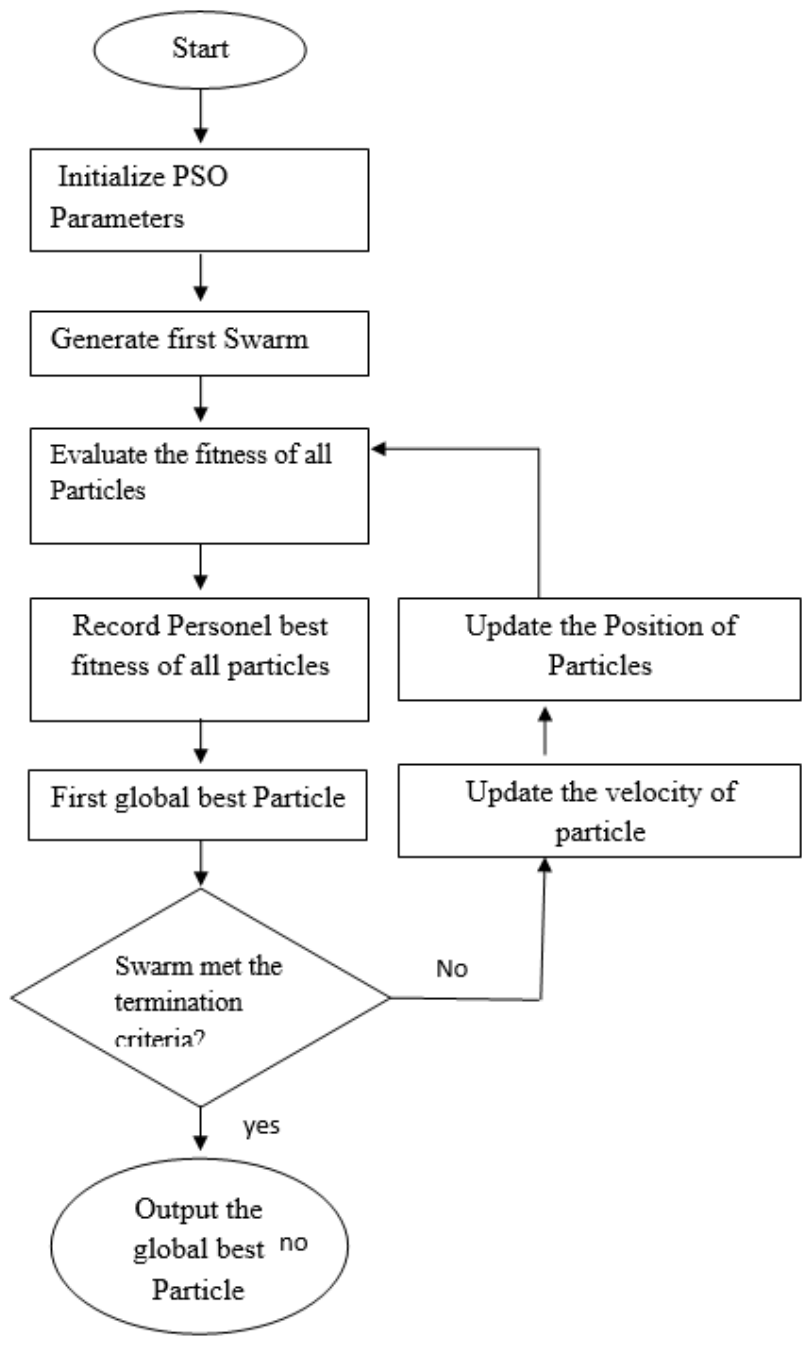

Figure 10: Flowchart of PSO algorithm.

sic concepts of PSO by Kennedy and Eberhart (1995). Although these simple rules model the behaviour of individuals, their combination produces a complicated behaviour for the swarm.

1. Individuals avoid collision with others

2. Individuals go towards the goal of the swarm

3. Individuals go to the centre of the swarm

The process of decision-making related to individuals is another basic concept of PSO. Each individual of the swarm makes decisionbased on the following two factors:

1. Own experiences of the individual that is its bestresults so far

2. The experiences of other individuals in the swarm that is the best results in the whole swarm

Figure 10 illustrates the standard flowchart of PSO. At the starting step of the original PSO, a certain num- 


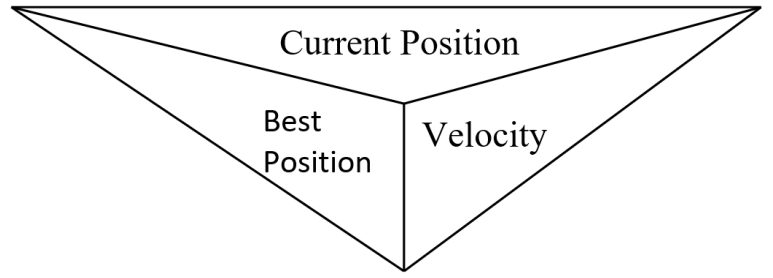

Figure 11: Schematic structure of a particle in PSO (Kalatehjari 2013).

ber of individuals, called particles, are distributed in the search space by using a random pattern (Kennedy and Eberhart 1995; Cheng et al. 2007; Aote et al. 2013). Each particle is representative of a feasible solution. Figure 11 shows the schematic structure of a particle in PSO involving three divided parts as its current position, best position and velocity. The current position, best position and velocity of particles record the current coordinates, best coordinates and velocity vectors of a particle in D-dimensional space,respectively, where D starts from 1 (Kalatehjari 2013). Consequently, for a particle in D-dimensional space, a 3D-dimensional particle is desirable. PSO aims to meet the termination criteria which are defined as the criteria for terminating the iterative search process. To select an appropriate termination criterion, it should be noted that the termination condition does not cause a premature converge and it should protect against oversampling of the fitness (Engelbrecht 2007). The following termination criteria are frequently used in PSO:

1. Termination when the maximum number ofiterations is exceeded

2. Termination when a satisfactory solution isfound based on the condition of each problem

3. Termination when no improvement is achievedover a certain number of iterations

These criteria are applied to ensure that PSO can converge on a feasible solution. Although PSO has some limitation which is explained by Gbenga et al. (2016) and Aote et al. (2013), PSO tries to make the objective function as a minimum or maximum dependingon the problem to be solved. To lead the swarm towards this aim, the fitness value of each particle is determined by evaluating its current position by the objective function. After evaluation offitness of all particles, Equation 39 (velocity equation) is used to calculate the velocity of particles based on their best position and the position of the best particle in the swarm.Using Equation 40, particle positions can be updated according to their current positions and velocities. This iterative process continues until reaching the termination criteria. Equations 39 and 40 are as follows (Kennedy and Eberhart 1995):

$$
\begin{gathered}
v_{n(i)}=v_{n(i-1)}+u\left(0, \vartheta_{1}\right)\left(b_{p_{n(i)}}-X_{n(i)}\right)+ \\
+u\left(0, \vartheta_{2}\right)\left(b_{g_{n(i)}}-X_{n(i)}\right) \\
X_{n(i+1)}=X_{n(i)}+v_{n(i)}
\end{gathered}
$$

where $v$ is the velocity of an $n$th particle in the past iteration and $v_{(n-1)}$ is the velocity of the $n$th particle in the current iteration. The vectors of random numbers ofan $n^{\text {th }}$ particle are presented by $u\left(0, \vartheta_{1}\right)$ and $u\left(0, \vartheta_{2}\right), b_{p_{n(i)}}$ is the best position of the $n$th particle so far, $b_{g_{n(i)}}$ is the position of the best particle of the swarm so far, and $X_{n(i-1)}$ and $X_{n(i)}$ are the positions of the $n$th particle in the current and next iterations, respectively. Input parameters are taken for optimisation as follows:

$$
\begin{aligned}
& \text { Input } h_{1} / B_{0}, \phi_{2}, \phi_{1} / \phi_{2}, \delta_{2}, \delta_{1} / \delta_{2}, 2 \bar{c} / \bar{\gamma} B_{0}, \\
& k_{h}, k_{v}, \xi, \alpha_{A 1}=20^{0}-80^{0} \alpha_{A 2}=30^{0}-80^{\circ} \\
& \alpha_{p 1}=30^{0}-80^{0} \alpha_{p 2}=30^{0}-60^{0}
\end{aligned}
$$

\subsection{Parametric study}

\subsubsection{Weak soil layer over strong soil layer}

Aparametric study was done for the variation of pseudostatic seismic bearing capacity coefficients with different soil parameters as shown in Figs 12-18.

\subsubsection{Variations of seismic bearing capacity coefficient for different values of slope angle (i) using PSO algorithm}

Figure 12 shows the variation of seismic bearing capacity coefficient $\left(N_{\gamma E}\right)$ at $\phi_{2}=30^{0}, \delta_{2}=\frac{\phi_{2}}{2}, \frac{\phi_{1}}{\phi_{2}}=0.8$, $\frac{\delta_{1}}{\delta_{2}}=0.8, k_{v}=\frac{k_{h}}{2}, \frac{\gamma_{1}}{\gamma_{2}}=0.8, \frac{D_{f}}{B_{0}}=0.5, \frac{h_{1}}{B_{0}}=0.5, \frac{2 c_{2}}{\gamma_{2} B_{0}}=0.2$ and $\frac{c_{1}}{c_{2}}=0.8$ with $k_{h}$. From the plot, it is seen that $N_{\gamma E}$ decreases with the increase of angle of inclination (i). As the slope angle is increased, the area of the slope is decreased; therefore, the failure zone is decreased, resulting in much smaller bearing capacity.

\subsubsection{Variations of seismic bearing capacity coefficient for different values of $\frac{\phi_{1}}{\phi_{2}}$ using PSO algorithm}

Figure 13 depicts the variations of seismic bearing capacity coefficient $\left(N_{\gamma E}\right)$ at $\phi_{2}=30^{0}, \delta_{2}=\frac{\phi_{2}}{2}, i=15^{0}, \frac{\delta_{1}}{\delta_{2}}=0.8$, 


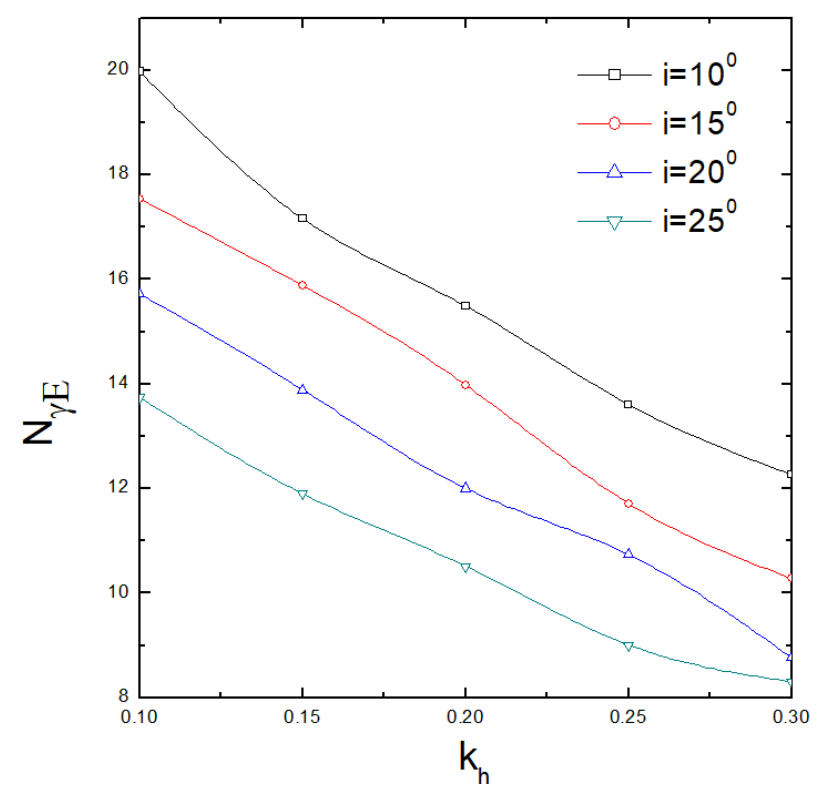

Figure 12: Variation of $\mathrm{N}_{\gamma \mathrm{E}}$ with $\mathrm{k}_{\mathrm{h}}$ for $\phi_{2}=30^{\circ}, \delta_{2}=\phi_{2} / 2$, $\phi_{1} / \phi_{2}=0.8, \delta_{1} / \delta_{2}=0.8, \mathrm{k}_{\mathrm{v}}=\mathrm{k}_{\mathrm{h}} / 2, \gamma_{1} / \gamma_{2}=0.8, \mathrm{D}_{\mathrm{f}} / \mathrm{B}_{0}=$ $0.5, \mathrm{~h}_{1} / \mathrm{B}_{0}=0.25,2 \mathrm{c}_{2} / \mathrm{B}_{0} \gamma_{2}=0.2, \mathrm{c}_{1} / \mathrm{c}_{2}=0.8$.

$k_{v}=\frac{k_{h}}{2}, \frac{\gamma_{1}}{\gamma_{2}}=0.8, \frac{D_{f}}{B_{0}}=0.5, \frac{D_{f}}{B_{0}}=0.5, \frac{2 c_{2}}{\gamma_{2} B_{0}}=0.2$ and $\frac{c_{1}}{c_{2}}=0.80$ with $k_{h}$. From the plot, it is seen that $N_{\gamma E}$ increases with an increase in the value of $\frac{\phi_{1}}{\phi_{2}}$. An increase in $\frac{\phi_{1}}{\phi_{2}}$ ratio increases the strength of the soil (or internal resistance of the soil) against the shearing resistance, which results in increasing the bearing capacity. Here, $\phi_{1}$ value is increased while keeping the $\phi_{2}$ value constant.

\subsubsection{Variations of seismic bearing capacity coefficient for different values of $\frac{\gamma_{1}}{\gamma_{2}}$ using PSO algorithm}

Figure 14 shows the variations of seismic bearing capacity coefficient $\left(N_{\gamma E}\right)$ at $\phi_{2}=30^{0}, \delta_{2}=\frac{\phi_{2}}{2}, i=15^{0}, \frac{\delta_{1}}{\delta_{2}}=$ $0.8, k_{v}=\frac{k_{h}}{2}, \frac{\phi_{1}}{\phi_{2}}=0.8, \frac{h_{1}}{B_{0}}=0.25, \frac{D_{f}}{B_{0}}=0.5, \frac{2 c_{2}}{\gamma_{2} B_{0}}=0$ and $\frac{c_{1}}{c_{2}}=0$ with $k_{h}$. From the plot, it is seen that coefficient $N_{\gamma E}$ increases with an increase in the value of $\frac{\gamma_{1}}{\gamma_{2}}$. Here, the ratio $\frac{\gamma_{1}}{\gamma_{2}}$ is increased while keeping $\gamma_{2}$ as a constant.

\subsubsection{Variations of seismic bearing capacity coefficient for different values of $\frac{h_{1}}{B_{0}}$ using PSO algorithm}

Figure 15 shows the variations of seismic bearing capacity coefficient $\left(N_{\gamma E}\right)$ at $\phi_{2}=30^{0}, \delta_{2}=\frac{\phi_{2}}{2}, i=15^{0}, \frac{\delta_{1}}{\delta_{2}}=$ $0.8, k_{v}=\frac{k_{h}}{2}, \frac{\phi_{1}}{\phi_{2}}=0.8, \frac{\gamma_{1}}{\gamma_{2}}=0.80, \frac{D_{f}}{B_{0}}=0.5, \frac{2 c_{2}}{\gamma_{2} B_{0}}=0.2$ and $\frac{c_{1}}{c_{2}}=0.8$ with $k_{h}$. From the plot, it is seen that $N_{\gamma E}$ decreases with an increase in the value of $\frac{h_{1}}{B_{0}} \cdot h_{1}$ is the depth

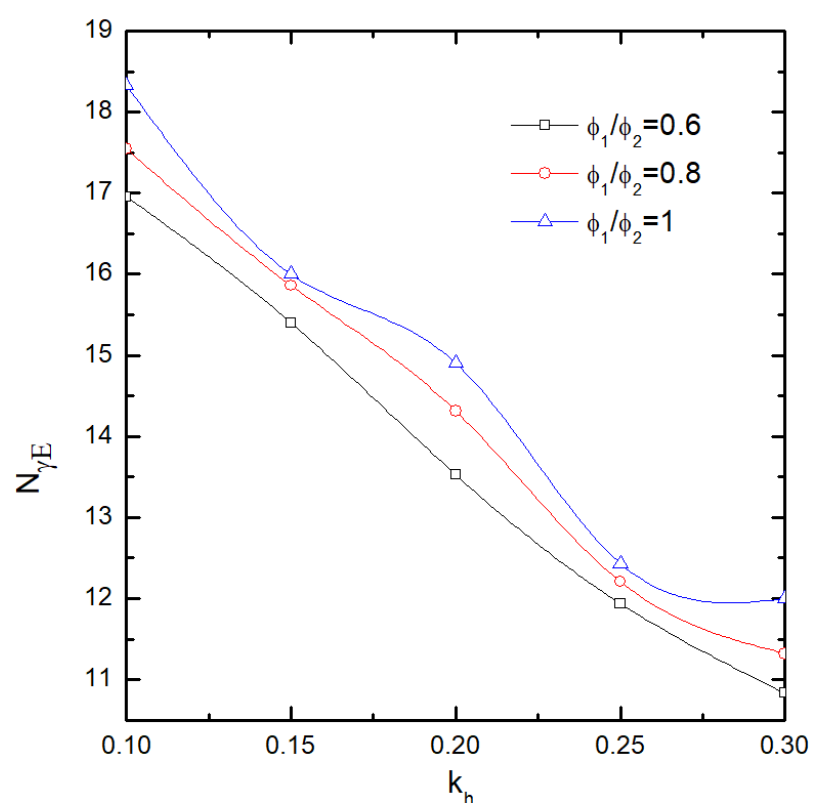

Figure 13: Variation of $\mathrm{N}_{\gamma \mathrm{E}}$ with $\mathrm{k}_{\mathrm{h}}$ for $\phi_{2}=30^{\circ}, \delta_{2}=\phi_{2} / 2, i=$ $15^{0}, \delta_{1} / \delta_{2}=0.8, \mathrm{k}_{\mathrm{v}}=\mathrm{k}_{\mathrm{h}} / 2, \gamma_{1} / \gamma_{2}=0.8, \mathrm{D}_{\mathrm{f}} / \mathrm{B}_{0}=0.5, \mathrm{~h}_{1} / \mathrm{B}_{0}=$ $0.25,2 \mathrm{c}_{2} / \mathrm{B}_{0} \gamma_{2}=0.2, \mathrm{c}_{1} \mathrm{c}_{2}=0.8$.

of the top layer and it is considered in the analysis that it is weaker than the bottom layer. So, a weaker layer will provide less resistance, and hence increase in the thickness of this layer decreases the value of bearing capacity coefficients.

\subsubsection{Variations of seismic bearing capacity coefficient for different values of $\frac{\delta_{1}}{\delta_{2}}$ using PSO algorithm}

Figure 16 shows the variation of seismic bearing capacity coefficient $\left(N_{\gamma E}\right)$ at $\phi_{2}=30^{\circ}, \delta_{2}=\frac{\phi_{2}}{2}, i=15^{0}, \frac{h_{1}}{B_{0}}=0.25$, $k_{v}=\frac{k_{h}}{2}, \frac{\phi_{1}}{\phi_{2}}=0.8, \frac{\gamma_{1}}{\gamma_{2}}=0.80, \frac{D_{f}}{B_{0}}=0.5, \frac{2 c_{2}}{\gamma_{2} B_{0}}=0.2$ and $\frac{c_{1}}{c_{2}}=0.8$ with $k_{h}$. From the plot, it is seen that coefficient $N_{\gamma E}$ increases with an increase in the value of $\frac{\delta_{1}}{\delta_{2}}$.

\subsubsection{Variations of seismic bearing capacity coefficient for different values of $\boldsymbol{k}_{v}$ using PSO algorithm}

Figure 17 shows the variation of $N_{\gamma E}$ at $\phi_{2}=30^{\circ}, \delta_{2}=\frac{\phi_{2}}{2}$, $i=15^{0}, \frac{h_{1}}{B_{0}}=0.25, \frac{c_{1}}{c_{2}}=0.80, \frac{\phi_{1}}{\phi_{2}}=0.8, \frac{\gamma_{1}}{\gamma_{2}}=0.80$, $\frac{D_{f}}{B_{0}}=0.5, \frac{2 c_{2}}{\gamma_{2} B_{0}}=0.2$ and $\frac{\delta_{1}}{\delta_{2}}=0.8$ with $k_{h}$. From the plot, it is seen that $N_{\gamma E}$ decreases with an increase in $k_{v}$. It is obvious because increase in the value of $k_{v}$ increases the disturbance of base soil and this decreases the value of $N_{\gamma E}$. 


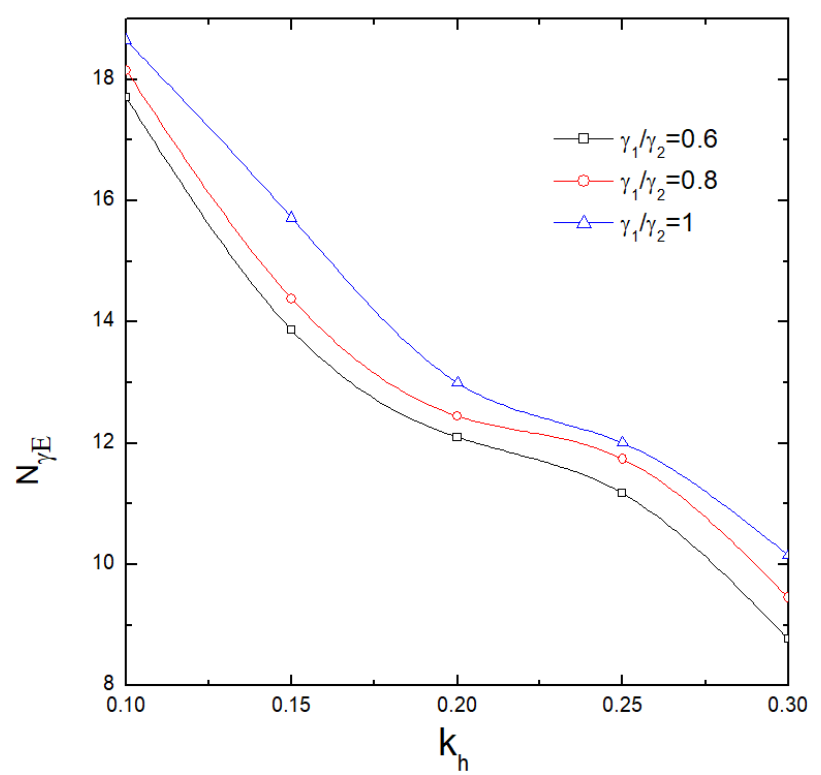

Figure 14: Variation of $N_{\gamma E}$ with $k_{h}$ for $\phi_{2}=30^{\circ}, \delta_{2}=\phi_{2} / 2, i=$ $15^{0}, \delta_{1} / \delta_{2}=0.8, \mathrm{k}_{\mathrm{V}}=\mathrm{k}_{\mathrm{h}} / 2, \phi_{1} / \phi_{2}=0.8, \mathrm{D}_{\mathrm{f}} / \mathrm{B}_{0}=0.5, \mathrm{~h}_{1} / \mathrm{B}_{0}=$ $0.25,2 \mathrm{c}_{2} / \mathrm{B}_{0} \gamma_{2}=0.2, \mathrm{c}_{1} / \mathrm{c}_{2}=0.8$.

\subsubsection{Variations of seismic bearing capacity coefficient for different values of $\frac{c_{1}}{c_{2}}$ using PSO algorithm}

Figure 18 shows the variation of $N_{\gamma E}$ at $\phi_{2}=30^{\circ}, \delta_{2}=\frac{\phi_{2}}{2}$, $i=15^{0}, \frac{h_{1}}{B_{0}}=0.25, k_{v}=\frac{k_{h}}{2}, \frac{\phi_{1}}{\phi_{2}}=0.8, \frac{\gamma_{1}}{\gamma_{2}}=0.80, \frac{D_{f}}{B_{0}}=$ $0.5, \frac{2 c_{2}}{\gamma_{2} B_{0}}=0.2$ and $\frac{\delta_{1}}{\delta_{2}}=0.8$ with $k_{h}$. From the plot, it is seen that the coefficient $N_{\gamma E}$ increases with an increase in the value of $\frac{c_{1}}{c_{2}}$. By increasing the $\frac{c_{1}}{c_{2}}$ ratio, intermolecular attraction among the soil particles increases, which results in an increase in the bearing capacity.

\subsubsection{Strong soil layer over weak soil layer}

\subsubsection{Variations of seismic bearing capacity coefficient for different values of using $\frac{\phi_{1}}{\phi_{2}}$ PSO algorithm}

Figure 19 depicts the variations of seismic bearing capacity coefficient $\left(N_{\gamma E}\right)$ at $\phi_{2}=20^{0}, \delta_{2}=\frac{\phi_{2}}{2}, \frac{h_{1}}{B_{0}}=0.25$, $\frac{\delta_{1}}{\delta_{2}}=1.1, k_{v}=\frac{k_{h}}{2}, \frac{\gamma_{1}}{\gamma_{2}}=1.1, \frac{D_{f}}{B_{0}}=0.5, \frac{2 c_{2}}{\gamma_{2} B_{0}}=0$ and $\frac{c_{1}}{c_{2}}=0$ with $k_{h}$. From the figure, it is seen that the coefficient $N_{\gamma E}$ increases with an increase in the value of $\frac{\phi_{1}}{\phi_{2}}$. As the upper layer is considered a strong layer for this parameter, increasing the internal soil friction bearing capacity will be increased. Here, the $\phi_{1}$ value is increased, keeping the $\phi_{2}$ value constant.

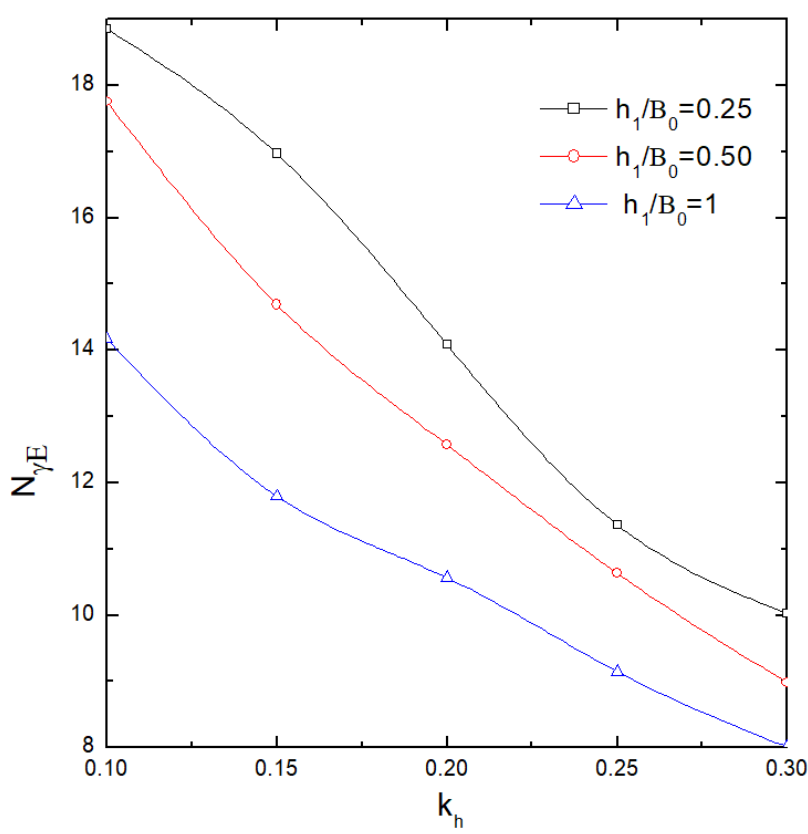

Figure 15: Variation of $\mathrm{N}_{\gamma \mathrm{E}}$ with $\mathrm{k}_{\mathrm{h}}$ for $\phi_{2}=30^{\circ}, \delta_{2}=\phi_{2} / 2, i=$ $15, \delta_{1} / \delta_{2}=0.8, \mathrm{k}_{\mathrm{v}}=\mathrm{k}_{\mathrm{h}} / 2, \phi_{1} / \phi_{2}=0.8, \mathrm{D}_{\mathrm{f}} / \mathrm{B}_{0}=0.5, \gamma_{1} / \gamma_{2}=$ $0.80,2 \mathrm{c}_{2} / \mathrm{B}_{0} \gamma_{2}=0.2, \mathrm{c}_{1} / \mathrm{c}_{2}=0.8$.

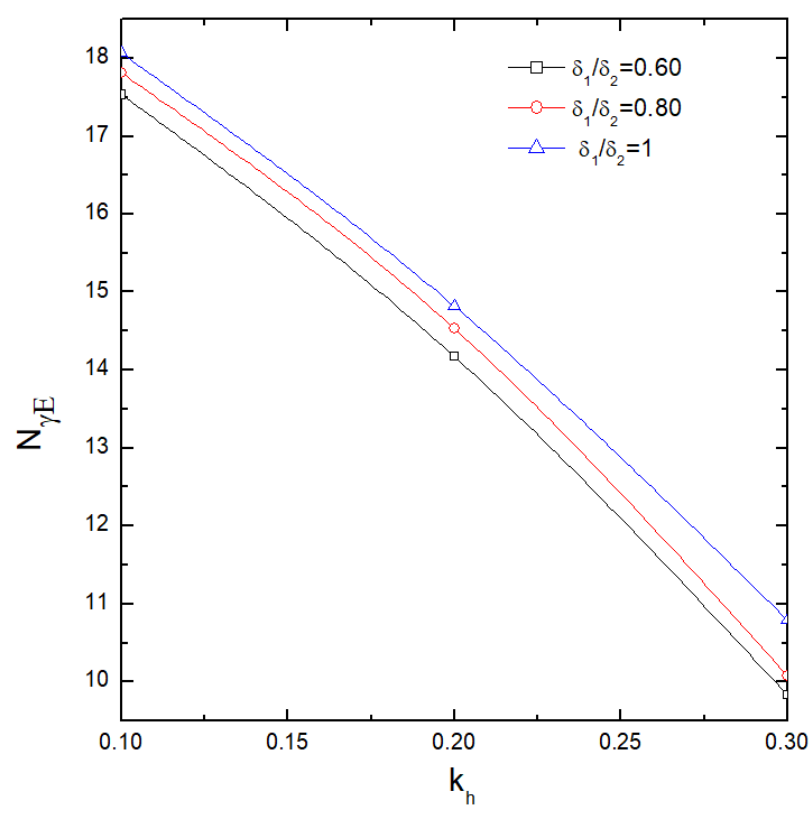

Figure 16: Variation of $\mathrm{N}_{\gamma \mathrm{E}}$ with $\mathrm{k}_{\mathrm{h}}$ for $\phi_{2}=30^{\circ}, \delta_{2}=\phi_{2} / 2 i=$ $15^{0}, \mathrm{c}_{2} / \mathrm{c}_{2}=0.8, \mathrm{k}_{\mathrm{V}}=\mathrm{k}_{\mathrm{h}} / 2, \phi_{1} / \phi_{2}=0.8, \mathrm{D}_{\mathrm{f}} / \mathrm{B}_{0}=0.5, \mathrm{~h}_{1} / \mathrm{B}_{0}=$ $0.25, \gamma_{1} / \gamma_{2}=0.8$. 


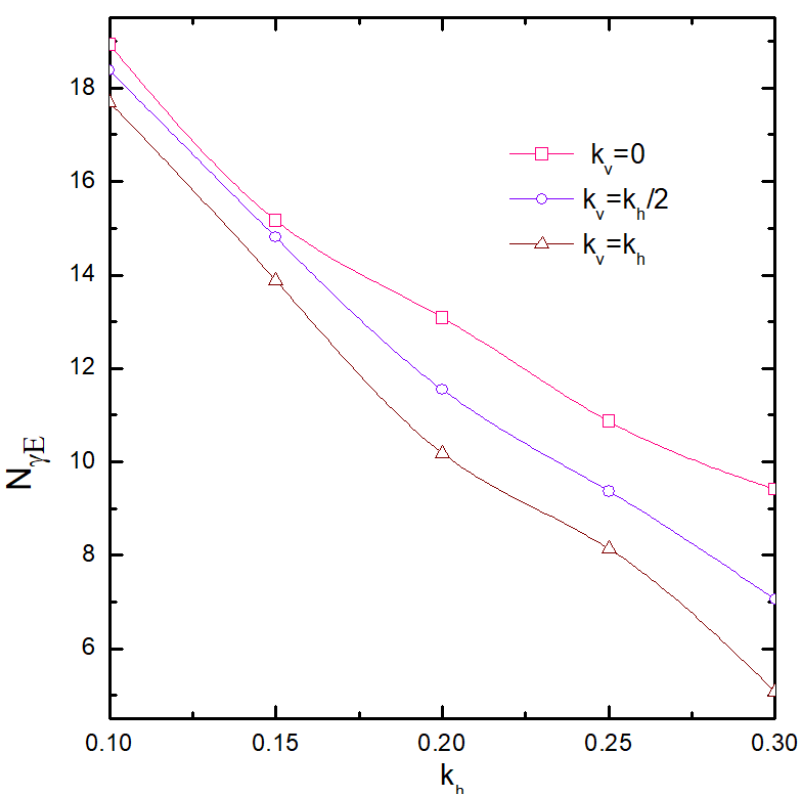

Figure 17: Variation of $N_{\gamma E}$ with $k_{h}$ for $\phi_{2}=30, \delta_{2}=\phi_{2} / 2, D_{f} / B_{0}=$ $0.5 \mathrm{i}=20^{\circ}, \mathrm{h}_{1} / \mathrm{B}_{0}=0.25, \gamma_{1} / \gamma_{2}=0.8, \delta_{1} / \delta_{2}=0.8, \phi_{1} / \phi_{2}=$ $0.8,2 \mathrm{c}_{2} / \mathrm{B}_{0} \gamma_{2}=0, \mathrm{c}_{1} / \mathrm{c}_{2}=0$.

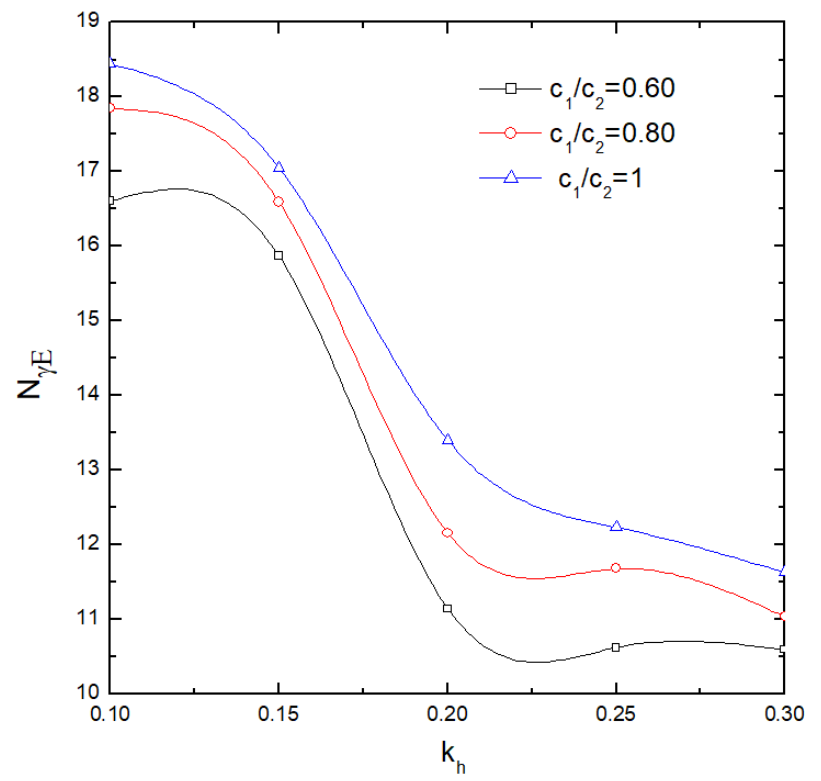

Figure 18: Variation of $\mathrm{N}_{\gamma \mathrm{E}}$ with $\mathrm{k}_{\mathrm{h}}$ for $\phi_{2}=30^{\circ}, \delta_{2}=\phi_{2} / 2 i=$ $15^{0}, \delta_{1} / \delta_{2}=0.8, \mathrm{k}_{\mathrm{V}}=\mathrm{k}_{\mathrm{h}} / 2, \phi_{1} / \phi_{2}=0.8, \mathrm{D}_{\mathrm{f}} / \mathrm{B}_{0}=0.5, \mathrm{~h}_{1} / \mathrm{B}_{0}=$ $0.25, \gamma_{1} / \gamma_{2}=0.8$.

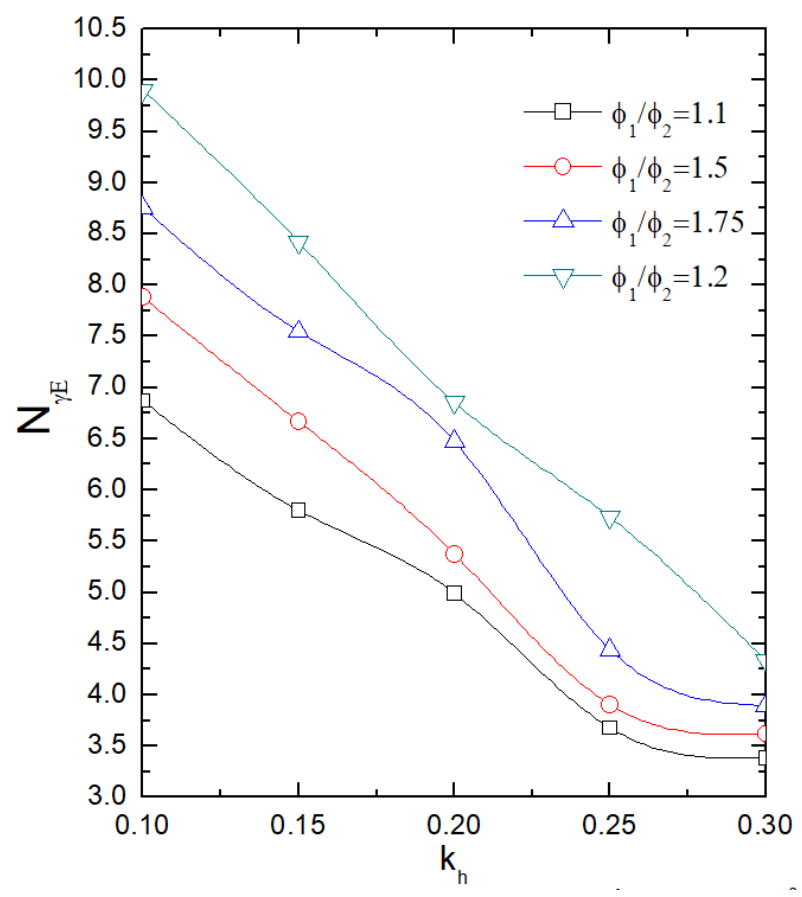

Figure 19: Variation of $\mathrm{N}_{\gamma \mathrm{E}}$ with $\mathrm{k}_{\mathrm{h}}$ for $\phi_{2}=20^{\circ}, \delta_{2}=\phi_{2} / 2, \mathrm{i}=20^{\circ}$ $\delta_{1} / \delta_{2}=1.1, \mathrm{k}_{\mathrm{v}}=\mathrm{k}_{\mathrm{h}} / 2, \gamma_{1} / \gamma_{2}=1.1, \mathrm{D}_{\mathrm{f}} / \mathrm{B}_{0}=0.50,2 \mathrm{c}_{2} / \mathrm{B}_{0} \gamma_{2}=$ $0, \mathrm{c}_{1} / \mathrm{c}_{2}=0$.

\subsubsection{Variations of seismic bearing capacity coefficient for different values of using $\frac{\gamma_{1}}{\gamma_{2}}$ PSO algorithm}

Figure 20 shows the variations of seismic bearing capacity coefficient $\left(N_{\gamma E}\right)$ at $\phi_{2}=30^{0}, \delta_{2}=\frac{\phi_{2}}{2}, \frac{h_{1}}{B_{0}}=0.25, \frac{\delta_{1}}{\delta_{2}}=$ $1.1, k_{v}=\frac{k_{h}}{2}, \frac{\phi_{1}}{\phi_{2}}=1.1, \frac{D_{f}}{B_{0}}=0.5, \frac{2 c_{2}}{\gamma_{2} B_{0}}=0$ and $\frac{c_{1}}{c_{2}}=0$ with $k_{h}$. From the figure, it is seen that the coefficient $N_{\gamma E}$ increases with an increase in the value of $\frac{\gamma_{1}}{\gamma_{2}}$. The ratio $\frac{\gamma_{1}}{\gamma_{2}}$ is increased keeping $\gamma_{2}$ as a constant. Here, $\gamma_{1}$ is the unit weight of the strong soil layer and $\gamma_{2}$ is the unit weight of the weak soil layer.

\subsubsection{Variations of seismic bearing capacity coefficient for different values of $\frac{c_{1}}{c_{2}}$ using PSO algorithm}

Figure 21 shows the variations of $\left(N_{\gamma E}\right)$ at $\phi_{2}=30^{0}, \delta_{2}=$ $\frac{\phi_{2}}{2}, \frac{h_{1}}{B_{0}}=0.25, \frac{\delta_{1}}{\delta_{2}}=1.1, k_{v}=\frac{k_{h}}{2}, \frac{\gamma_{1}}{\gamma_{2}}=1.1, \frac{D_{f}}{B_{0}}=0.5$, $\frac{2 c_{2}}{\gamma_{2} B_{0}}=0.2, \frac{\phi_{1}}{\phi_{2}}=0$ with $k_{h}$. From the plot, it is seen that the coefficient $N_{\gamma E}$ increases with an increase in the values of $\frac{\mathbf{c}_{1}}{\mathbf{c}_{2}}$. Here, $c_{2}$ is the cohesive force on the weak soil layer and $c_{1}$ is the cohesive force on the strong soil layer. Hence, the ratio $\frac{\mathbf{c}_{1}}{\mathbf{c}_{\mathbf{2}}}$ is increased while keeping $c_{2}$ constant. So, the value $N_{\gamma E}$ will increase. 
Table 3: Comparison of variation of seismic bearing capacity $\left(q_{u E}\right) \mathrm{KN} / \mathrm{m}^{2}$ with $\gamma\left(\mathrm{KN} / \mathrm{m}^{3}\right)$ for the case of $\phi=30^{\circ}, c=9.8 \mathrm{KN} / \mathrm{m}^{2}, i=$ $20^{\circ}, B_{0}=10 \mathrm{~m}$.

\begin{tabular}{lllllllll}
\hline & \multicolumn{2}{c}{ Sawada et al. (1994) } & \multicolumn{2}{c}{ Askari and Farzaneh (2003) } & \multicolumn{2}{c}{ Yamamoto (2010) } & \multicolumn{2}{c}{ Present Analysis } \\
$\mathrm{k}_{\mathrm{h}}$ & $\gamma=9.8$ & $\gamma=19.8$ & $\gamma=9.8$ & $\gamma=19.8$ & $\gamma=9.8$ & $\gamma=19.8$ & $\gamma=9.8$ & $\gamma=19.8$ \\
\hline 0.1 & 1798 & 3321 & 1066 & 1856 & 1013 & 1795 & 1614.14 & 3139.92 \\
0.2 & 1770 & 3269 & 829 & 1307 & 755 & 1283 & 654 & 1167 \\
\hline
\end{tabular}

Table 4: Comparison of the variation in $N_{c s}$ with different $c_{u} / \gamma B_{0}, D_{f} / B_{0}, c_{1} / c_{2}$ for $i=30^{\circ}$.

\begin{tabular}{|c|c|c|c|c|c|c|c|c|}
\hline \multirow[b]{2}{*}{$\mathrm{C}_{\mathrm{u}} / \gamma \mathrm{B}_{0}$} & \multicolumn{4}{|c|}{$\mathrm{N}_{\mathrm{cs}}$ (Present study) } & \multicolumn{4}{|c|}{$\mathrm{N}_{\mathrm{cs}}(\mathrm{Wu}$ et al. 2020) } \\
\hline & $\begin{array}{l}D_{f} / B_{0}=0.5, \\
c_{1} / c_{2}=0.5\end{array}$ & $\begin{array}{l}D_{f} / B_{0}=1.5, \\
c_{1} / C_{2}=0.5\end{array}$ & $\begin{array}{l}D_{f} / B_{0}=1.5, \\
C_{1} / C_{2}=1.5\end{array}$ & $\begin{array}{l}D_{f} / B_{0}=0.5, \\
C_{1} / C_{2}=1.5\end{array}$ & $\begin{array}{l}D_{f} / B_{0}=0.5, \\
C_{1} / C_{2}=0.5\end{array}$ & $\begin{array}{l}D_{f} / B_{0}=1.5, \\
C_{1} / C_{2}=0.5\end{array}$ & $\begin{array}{l}D_{f} / B_{0}=1.5, \\
c_{1} / C_{2}=1.5\end{array}$ & $\begin{array}{l}D_{f} / B_{0}=0.5 \\
C_{1} / c_{2}=1.5\end{array}$ \\
\hline 1 & 4.06 & 3.78 & 2.78 & 2.34 & 4.05 & 3.79 & 2.8 & 2.34 \\
\hline 2 & 4.15 & 3.92 & 3.05 & 2.95 & 4.16 & 3.96 & 3.01 & 3.01 \\
\hline 4 & 4.20 & 4.02 & 3.11 & 3.04 & 4.19 & 4.02 & 3.12 & 3.12 \\
\hline 6 & 4.22 & 4.04 & 3.22 & 3.10 & 4.2 & 4.04 & 3.15 & 3.15 \\
\hline 8 & 4.24 & 4.06 & 3.23 & 3.14 & 4.21 & 4.05 & 3.17 & 3.17 \\
\hline 10 & 4.25 & 4.08 & 3.24 & 3.16 & 4.22 & 4.6 & 3.17 & 3.17 \\
\hline
\end{tabular}

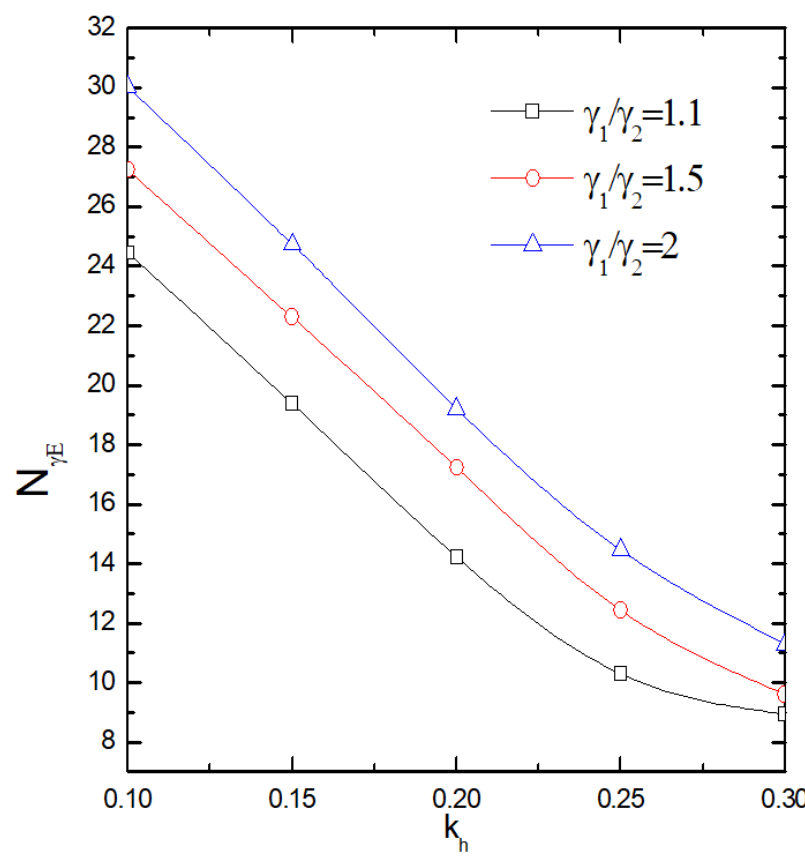

Figure 20: Variation of $\mathrm{N}_{\gamma \mathrm{E}}$ with $\mathrm{k}_{\mathrm{h}}$ for $\phi_{2}=30^{\circ}, i=20^{\circ}, \delta_{2}=$ $\phi_{2} / 2, \mathrm{~h}_{1} / \mathrm{B}_{0}=0.25, \delta_{1} / \delta_{2}=1.1, \mathrm{k}_{\mathrm{v}}=\mathrm{k}_{\mathrm{h}} / 2, \phi_{1} / \phi_{2}=1.1, \mathrm{D} / \mathrm{B}_{0}=$ $0.50,2 \mathrm{c}_{2} / \mathrm{B}_{0} \gamma_{2}=0, \mathrm{c}_{1} / \mathrm{c}_{2}=0$.

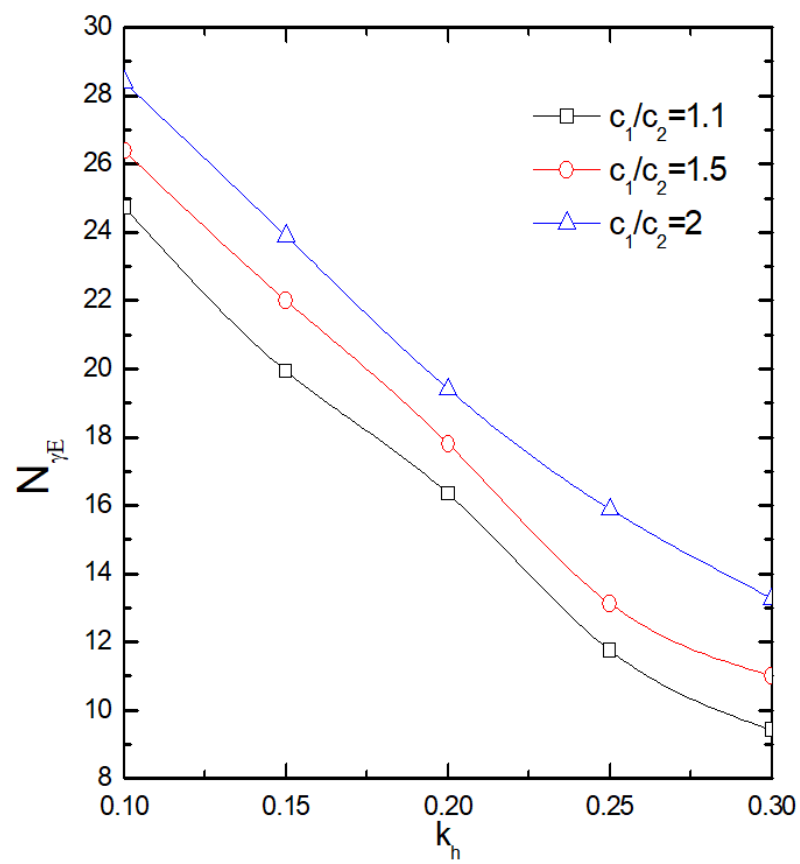

Figure 21: Variation of $\mathrm{N}_{\gamma \mathrm{E}}$ with $\mathrm{k}_{\mathrm{h}}$ for $\phi_{2}=30^{\circ}, \mathrm{i}=20^{\circ}, \delta_{2}=$ $\phi_{2} / 2, \mathrm{~h}_{1} / \mathrm{B}_{0}=0.25, \delta_{1} / \delta_{2}=1.1, \mathrm{k}_{\mathrm{v}}=\mathrm{k}_{\mathrm{h}} / 2, \phi_{1} / \phi_{2}=1.1, \mathrm{D} / \mathrm{B}_{0}=$ $0.50, \gamma_{1} / \gamma_{2}=1.1$. 


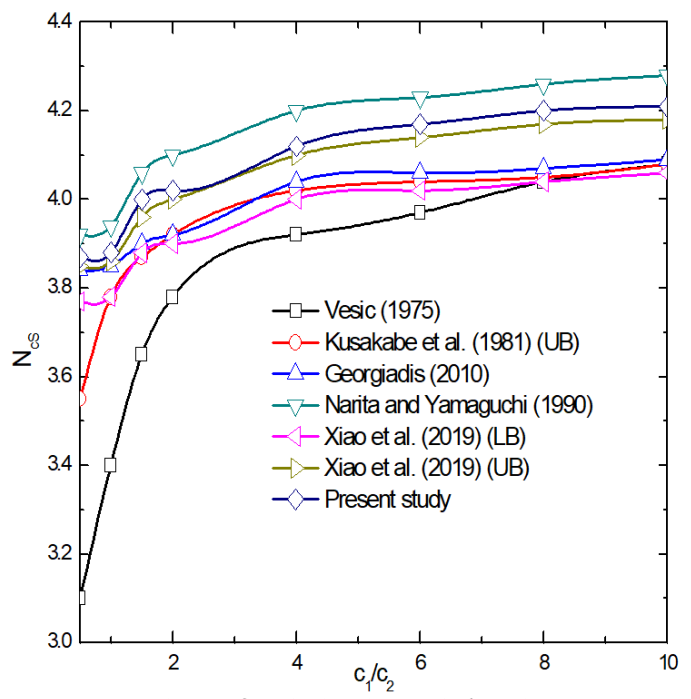

Figure 22: Comparison of variation in static bearing capacity coefficients $\left(\mathrm{N}_{\mathrm{C}} \mathrm{S}\right)$ with $\mathrm{c}_{1} / \mathrm{c}_{2}$ for $\mathrm{i}=30^{\circ}$.

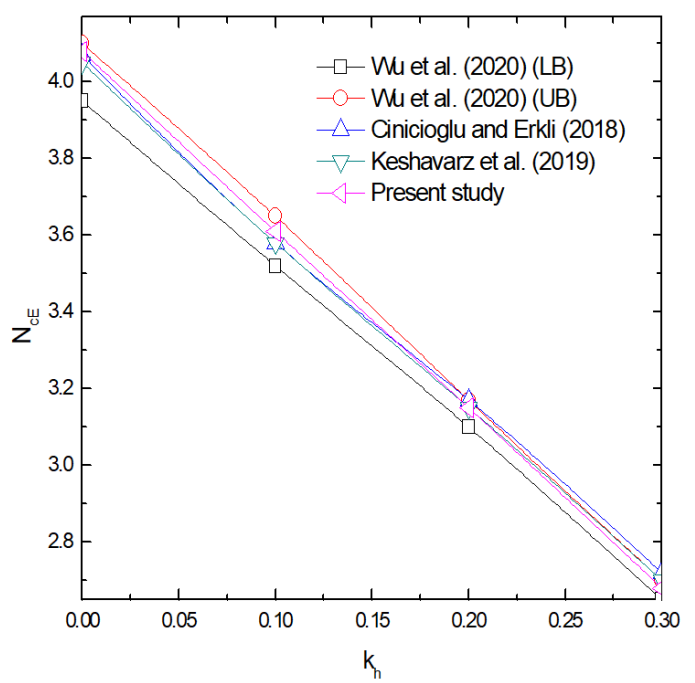

Figure 23: Comparison of seismic bearing capacity coefficients $\left(\mathrm{N}_{\mathrm{cE}}\right)$ with $\mathrm{k}_{\mathrm{h}}$ for $\mathrm{D}_{\mathrm{f}} / \mathrm{B}_{0}=0, \mathrm{i}=30^{\circ}, \mathrm{c}_{1} / \mathrm{c}_{2}=1$.

\section{Comparisons}

The bearing capacity coefficient $\left(N_{\gamma^{\prime \prime}}\right)$ has been computed by using a computer programing software 'MATLAB' code. PSO algorithm is applied, which can calculate the ultimate bearing capacity, $q_{\text {ult }}$, for various combinations of soil properties in each layer. Table 3 shows a comparison of the ultimate bearing capacity for $D_{f} / B_{0}=0.25$ between Askari and Farzaneh (2003), Sawada et al. (1994), Yamamoto (2010) and the present analysis,demonstrating the potentiality of the present analysis. It is found that the solutions from Sawada et al. (1994) have high values with the increase of $\gamma$, compared with those from Askari and Farzaneh (2003), Yamamoto (2010) and the present analysis. This fact depends on the assumed failure mechanism. For the case of $\gamma=9.8,19.8$, the solutions from the present analysis tend to have lower values than those from Askari and Farzaneh (2003). The proposed solutions of the footing at two-layered slope with different $c_{u} / \gamma B_{0}$, $\mathrm{D}_{\mathrm{f}} / \mathrm{B}_{0}$ and $\mathrm{c}_{1} / \mathrm{c}_{2}$ are compared with the results of $\mathrm{Wu}$ et al. (2020), as shown in Table 4. These results are compared for bearing capacity coefficient $\left(N_{c S}\right)$. The undrained seismic bearing capacity coefficients can be written as: $N_{c s}=q_{u l t} / c_{1}=f\left(c_{u} / \gamma B_{0}, D_{f} / B_{0}, c_{1} / c_{2}, i, k_{h}\right) . q_{u l t}$ is the ultimate bearing capacity of the strip footing. The cases of footings lying on two-layered level ground with the seismic action are compared with the results of Jahani et al. (2019), and the comparison is presented in Table 5. It is observed from Table 5 that the results of the present study agree well with those of previous studies. Consequently, Tables 6-8 display comparisons of the variation in $N_{c s}$ with Xiao et al. (2019) for different slope angles $i=15^{\circ}, 30^{\circ}$ and $45^{\circ}$. The undrained static bearing capacity factors for cohesion $\left(N_{c s}\right)$ obtained in the present study for a footing of uniform slope were compared with the UB and LB solutions of Xiao et al. (2019), semi-empirical results reported by Vesic (1975), the upper bound (UB) solutions obtained from Kusakabe et al. (1981), the limit-equilibrium methods of Narita and Yamaguchi (1990) and the finite element results provided by Georgiadis (2010). Comparison of these results is shown in Fig. 22 for the case of slope angle $(i)=30^{\circ}$. In Fig. 22, it is observed that the values of $N_{C S}$ obtained from the UB solutions of Kusakabe et al. (1981) and Georgiadis (2010) lie between the UB and LB solutions of Xiao et al. (2019). The semi-empirical solutions of Vesic (1975) give the lowest values, whereas the values reported by Narita and Yamaguchi (1990) are found to be the highest dimensionless bearing capacity coefficients. From this figure, it is also observed that the values obtained in the present study are closer to the UB solutions obtained by Xiao et al. (2019) and Narita and Yamaguchi (1990). The present values lie between these two researches' values. To verify the reliability of the present model, the LB and UB results were compared with the present limit equilibrium method. The present model of $D_{f} / B_{0}=0, i=$ $30^{\circ}$ and $c_{1} / c_{2}=1$ with different seismic coefficients $k_{h}$ were compared with the previous $\mathrm{LB}$ and UB results ( $\mathrm{Wu}$ et al. 2020), FEM results (Cinicioglu and Erkli 2018) and FELA results (Keshavarz et al. 2019). It can be seen in Fig. 23 that the present seismic bearing capacity coefficients $\left(\mathrm{N}_{\mathrm{cE}}\right)$ closely match with the Upper bound (UB) limit analysis values.Based on the comparisons mentioned above, the proposed model can be proved with relatively minor error. 
Table 5: Comparison of the variation in $N_{c s}$ with different $k_{h}$ and $c_{1} / c_{2}$ for $i=0^{\circ}$ and $D_{f} / B_{0}$.

\begin{tabular}{lllllll}
\hline & \multicolumn{3}{c}{$\mathrm{N}_{\text {cS }}$ (Present study) } & \multicolumn{4}{c}{$\mathrm{N}_{\text {cs }}$ (Jahani et al. 2019) } \\
\cline { 2 - 7 } $\mathrm{k}_{\mathrm{h}}$ & $\mathrm{c}_{1} / \mathrm{c}_{2}=0.25$ & $\mathrm{c}_{1} / \mathrm{c}_{2}=0.50$ & $\mathrm{c}_{1} / \mathrm{c}_{2}=0.75$ & $\mathrm{c}_{1} / \mathrm{c}_{2}=0.25$ & $\mathrm{c}_{1} / \mathrm{c}_{2}=0.50$ & $\mathrm{c}_{1} / \mathrm{c}_{2}=0.75$ \\
\hline 0 & 5.62 & 3.94 & 3.06 & 5.67 & 4 & 3.1 \\
0.1 & 5.20 & 3.48 & 2.75 & 5.25 & 3.58 & 2.73 \\
0.2 & 4.04 & 3.04 & 2.37 & 4.44 & 3.12 & 2.4 \\
0.3 & 3.38 & 2.65 & 2.12 & 3.47 & 2.7 & 2.15 \\
\hline
\end{tabular}

Table 6: Comparison of the variation in $\mathrm{N}_{\mathrm{cs}}$ for $\mathrm{i}=15^{\circ}$.

\begin{tabular}{|c|c|c|c|c|c|c|c|c|c|c|}
\hline \multirow{3}{*}{$h_{1} / B_{0}$} & \multirow{3}{*}{$D_{f} / B_{0}$} & \multirow{3}{*}{$c_{1} / c_{2}$} & \multicolumn{4}{|c|}{ Xiao et al. (2019) } & \multicolumn{4}{|c|}{ Present study } \\
\hline & & & \multicolumn{4}{|c|}{$\mathrm{c}_{1} / \gamma \mathrm{B}_{0}$} & \multicolumn{4}{|c|}{$\mathrm{c}_{1} / \gamma \mathrm{B}_{0}$} \\
\hline & & & 1 & 2 & 4 & 6 & 1 & 2 & 4 & 6 \\
\hline \multirow{8}{*}{0.5} & \multirow{4}{*}{0.25} & 0.25 & 5.71 & 5.73 & 5.74 & 5.74 & 5.68 & 5.70 & 5.71 & 5.72 \\
\hline & & 0.5 & 5.71 & 5.73 & 5.74 & 5.74 & 5.68 & 5.70 & 5.71 & 5.72 \\
\hline & & 0.75 & 5.53 & 5.57 & 5.58 & 5.59 & 5.49 & 5.55 & 5.56 & 5.57 \\
\hline & & 1 & 4.51 & 4.58 & 4.61 & 4.63 & 4.49 & 4.53 & 4.58 & 4.60 \\
\hline & \multirow{4}{*}{0.50} & 0.25 & 4.70 & 4.75 & 4.77 & 4.77 & 4.68 & 4.71 & 4.74 & 4.74 \\
\hline & & 0.5 & 4.70 & 4.75 & 4.77 & 4.77 & 4.68 & 4.72 & 4.75 & 4.75 \\
\hline & & 0.75 & 4.70 & 4.74 & 4.77 & 4.77 & 4.68 & 4.71 & 4.75 & 4.75 \\
\hline & & 1 & 4.51 & 4.57 & 4.61 & 4.62 & 4.45 & 4.51 & 4.59 & 4.59 \\
\hline \multirow{8}{*}{1} & \multirow{4}{*}{0.25} & 0.25 & 5.71 & 5.73 & 5.73 & 5.75 & 5.68 & 5.70 & 5.71 & 5.72 \\
\hline & & 0.5 & 5.71 & 5.73 & 5.73 & 5.74 & 5.68 & 5.70 & 5.70 & 5.71 \\
\hline & & 0.75 & 5.52 & 5.57 & 5.58 & 5.59 & 5.50 & 5.55 & 5.56 & 5.57 \\
\hline & & 1 & 4.51 & 4.58 & 4.61 & 4.63 & 4.48 & 4.55 & 4.59 & 4.61 \\
\hline & \multirow{5}{*}{0.50} & 0.25 & 4.70 & 4.75 & 4.77 & 4.78 & 4.68 & 4.72 & 4.74 & 4.75 \\
\hline & & 0.5 & 4.71 & 4.75 & 4.77 & 4.78 & 4.67 & 4.74 & 4.75 & 4.76 \\
\hline & & 0.75 & 4.70 & 4.75 & 4.77 & 4.78 & 4.66 & 4.74 & 4.74 & 4.75 \\
\hline & & 1 & 4.51 & 4.58 & 4.62 & 4.62 & 4.49 & 4.55 & 4.60 & 4.61 \\
\hline \multirow{8}{*}{2} & & 0.25 & 5.71 & 5.73 & 5.74 & 5.73 & 5.69 & 5.72 & 5.72 & 5.73 \\
\hline & \multirow{3}{*}{0.25} & 0.5 & 5.71 & 5.73 & 5.74 & 5.74 & 5.69 & 5.71 & 5.72 & 5.73 \\
\hline & & 0.75 & 5.52 & 5.57 & 5.58 & 5.59 & 5.50 & 5.55 & 5.56 & 5.57 \\
\hline & & 1 & 4.51 & 4.58 & 4.62 & 4.63 & 5.49 & 5.53 & 5.54 & 5.55 \\
\hline & \multirow{4}{*}{0.50} & 0.25 & 4.70 & 4.74 & 4.77 & 4.79 & 4.69 & 4.72 & 4.75 & 4.77 \\
\hline & & 0.5 & 4.70 & 4.76 & 4.77 & 4.77 & 4.68 & 4.70 & 4.73 & 4.75 \\
\hline & & 0.75 & 4.70 & 4.74 & 4.76 & 4.78 & 4.67 & 4.68 & 4.70 & 4.72 \\
\hline & & 1 & 4.51 & 4.58 & 4.61 & 4.62 & 4.47 & 4.54 & 4.59 & 4.60 \\
\hline \multirow{8}{*}{3} & \multirow{4}{*}{0.25} & 0.25 & 5.70 & 5.73 & 5.74 & 5.74 & 5.69 & 5.71 & 5.72 & 5.72 \\
\hline & & 0.5 & 5.70 & 5.73 & 5.74 & 5.74 & 5.69 & 5.71 & 5.72 & 5.72 \\
\hline & & 0.75 & 5.52 & 5.56 & 5.58 & 5.58 & 5.50 & 5.55 & 5.56 & 5.57 \\
\hline & & 1 & 4.51 & 4.58 & 4.61 & 4.62 & 4.48 & 4.55 & 4.58 & 4.60 \\
\hline & \multirow{4}{*}{0.50} & 0.25 & 4.71 & 4.75 & 4.77 & 4.78 & 4.69 & 4.72 & 4.74 & 4.77 \\
\hline & & 0.5 & 4.70 & 4.75 & 4.77 & 4.78 & 4.68 & 4.72 & 4.74 & 4.77 \\
\hline & & 0.75 & 4.70 & 4.75 & 4.77 & 4.77 & 4.67 & 4.71 & 4.73 & 4.73 \\
\hline & & 1 & 4.51 & 4.58 & 4.61 & 4.63 & 4.49 & 4.55 & 4.59 & 4.60 \\
\hline
\end{tabular}


Table 7: Comparison of the variation in $\mathrm{N}_{\mathrm{cs}}$ for $\mathrm{i}=30^{\circ}$.

\begin{tabular}{|c|c|c|c|c|c|c|c|c|c|c|}
\hline \multirow{3}{*}{$\mathrm{h}_{1} / \mathrm{B}_{0}$} & \multirow{3}{*}{$D_{f} / B_{0}$} & \multirow{3}{*}{$c_{1} / c_{2}$} & \multicolumn{4}{|c|}{ Xiao et al. (2019) } & \multicolumn{4}{|c|}{ Present study } \\
\hline & & & \multicolumn{4}{|c|}{$\mathrm{c}_{1} / \gamma \mathrm{B}_{0}$} & \multicolumn{4}{|c|}{$\mathrm{c}_{1} / \gamma \mathrm{B}_{0}$} \\
\hline & & & 1 & 2 & 4 & 6 & 1 & 2 & 4 & 6 \\
\hline \multirow{8}{*}{0.5} & \multirow{4}{*}{0.25} & 0.25 & 5.15 & 5.20 & 5.23 & 5.23 & 5.11 & 5.16 & 5.21 & 5.21 \\
\hline & & 0.5 & 5.15 & 5.20 & 5.22 & 5.23 & 5.11 & 5.16 & 5.21 & 5.20 \\
\hline & & 0.75 & 4.86 & 4.95 & 5.00 & 5.01 & 4.81 & 4.88 & 4.91 & 4.96 \\
\hline & & 1 & 3.88 & 4.01 & 4.07 & 4.09 & 3.82 & 4.01 & 4.03 & 4.05 \\
\hline & \multirow{4}{*}{0.50} & 0.25 & 4.09 & 4.18 & 4.23 & 4.24 & 4.05 & 4.16 & 4.20 & 4.21 \\
\hline & & 0.5 & 4.09 & 4.18 & 4.23 & 4.24 & 4.02 & 4.14 & 4.18 & 4.20 \\
\hline & & 0.75 & 4.09 & 4.18 & 4.23 & 4.24 & 4.01 & 4.12 & 4.16 & 4.18 \\
\hline & & 1 & 3.88 & 4.00 & 4.07 & 4.09 & 3.84 & 3.95 & 4.02 & 4.05 \\
\hline \multirow{9}{*}{1} & \multirow{4}{*}{0.25} & 0.25 & 5.15 & 5.20 & 5.22 & 5.23 & 5.10 & 5.15 & 5.20 & 5.21 \\
\hline & & 0.5 & 5.15 & 5.20 & 5.22 & 5.23 & 5.09 & 5.13 & 5.19 & 5.20 \\
\hline & & 0.75 & 4.85 & 4.95 & 5.00 & 5.01 & 4.80 & 4.85 & 4.90 & 4.93 \\
\hline & & 1 & 3.83 & 3.99 & 4.06 & 4.08 & 3.80 & 3.92 & 3.99 & 4.01 \\
\hline & \multirow{5}{*}{0.50} & 0.25 & 4.10 & 4.19 & 4.24 & 4.25 & 4.07 & 4.11 & 4.20 & 4.22 \\
\hline & & 0.5 & 4.10 & 4.19 & 4.23 & 4.25 & 4.05 & 4.10 & 4.19 & 4.20 \\
\hline & & 0.75 & 4.10 & 4.19 & 4.23 & 4.25 & 4.04 & 4.10 & 4.18 & 4.19 \\
\hline & & 1 & 3.83 & 3.99 & 4.06 & 4.08 & 3.80 & 3.95 & 4.04 & 4.06 \\
\hline & & 0.25 & 5.15 & 5.20 & 5.22 & 5.23 & 5.11 & 5.17 & 5.20 & 5.21 \\
\hline \multirow{7}{*}{2} & \multirow{3}{*}{0.25} & 0.5 & 5.15 & 5.20 & 5.22 & 5.23 & 5.10 & 5.17 & 5.20 & 5.21 \\
\hline & & 0.75 & 4.85 & 4.95 & 5.00 & 5.01 & 4.82 & 4.90 & 4.96 & 4.99 \\
\hline & & 1 & 3.83 & 3.99 & 4.06 & 4.08 & 3.81 & 3.95 & 4.01 & 4.04 \\
\hline & \multirow{4}{*}{0.50} & 0.25 & 4.09 & 4.19 & 4.23 & 4.25 & 4.07 & 4.15 & 4.20 & 4.22 \\
\hline & & 0.5 & 4.09 & 4.19 & 4.23 & 4.25 & 4.05 & 4.14 & 4.20 & 4.21 \\
\hline & & 0.75 & 4.09 & 4.19 & 4.23 & 4.25 & 4.05 & 4.14 & 4.20 & 4.21 \\
\hline & & 1 & 3.82 & 3.98 & 4.05 & 4.07 & 3.80 & 3.94 & 4.01 & 4.04 \\
\hline \multirow{8}{*}{3} & \multirow{4}{*}{0.25} & 0.25 & 5.16 & 5.20 & 5.22 & 5.23 & 5.11 & 5.18 & 5.20 & 5.21 \\
\hline & & 0.5 & 5.16 & 5.20 & 5.22 & 5.23 & 5.11 & 5.17 & 5.20 & 5.21 \\
\hline & & 0.75 & 4.85 & 4.95 & 5.00 & 5.01 & 4.81 & 4.92 & 4.99 & 5.00 \\
\hline & & 1 & 3.83 & 3.99 & 4.06 & 4.08 & 3.80 & 3.96 & 4.03 & 4.06 \\
\hline & \multirow{4}{*}{0.50} & 0.25 & 4.10 & 4.19 & 4.23 & 4.25 & 4.07 & 4.15 & 4.20 & 4.23 \\
\hline & & 0.5 & 4.09 & 4.19 & 4.23 & 4.24 & 4.06 & 4.14 & 4.20 & 4.22 \\
\hline & & 0.75 & 4.10 & 4.19 & 4.23 & 4.24 & 4.05 & 4.12 & 4.18 & 4.20 \\
\hline & & 1 & 3.83 & 3.99 & 4.06 & 4.08 & 3.80 & 3.93 & 4.03 & 4.06 \\
\hline
\end{tabular}


Table 8: Comparison of the variation in $\mathrm{N}_{\mathrm{cS}}$ for $\mathrm{i}=45^{\circ}$.

\begin{tabular}{|c|c|c|c|c|c|c|c|c|c|c|}
\hline \multirow{3}{*}{$h_{1} / B_{0}$} & \multirow{3}{*}{$D_{f} / B_{0}$} & \multirow{3}{*}{$c_{1} / c_{2}$} & \multicolumn{4}{|c|}{ Xiao et al. (2019) } & \multicolumn{4}{|c|}{ Present study } \\
\hline & & & \multicolumn{4}{|c|}{$\mathrm{c}_{1} / \gamma \mathrm{B}_{0}$} & \multicolumn{4}{|c|}{$\mathrm{c}_{1} / \gamma \mathrm{B}_{0}$} \\
\hline & & & 1 & 2 & 4 & 6 & 1 & 2 & 4 & 6 \\
\hline \multirow{8}{*}{0.5} & \multirow{4}{*}{0.25} & 0.25 & 4.57 & 4.63 & 4.66 & 4.67 & 4.54 & 4.60 & 4.62 & 4.64 \\
\hline & & 0.5 & 4.57 & 4.64 & 4.66 & 4.68 & 4.53 & 4.60 & 4.61 & 4.63 \\
\hline & & 0.75 & 4.23 & 4.34 & 4.40 & 4.41 & 4.21 & 4.31 & 4.37 & 4.40 \\
\hline & & 1 & 3.44 & 3.57 & 3.63 & 3.65 & 3.41 & 3.53 & 3.55 & 3.59 \\
\hline & \multirow{4}{*}{0.50} & 0.25 & 3.49 & 3.62 & 3.67 & 3.70 & 3.45 & 3.58 & 3.62 & 3.67 \\
\hline & & 0.5 & 3.49 & 3.61 & 3.67 & 3.70 & 3.44 & 3.59 & 3.60 & 3.67 \\
\hline & & 0.75 & 3.49 & 3.61 & 3.68 & 3.70 & 3.43 & 3.56 & 3.59 & 3.66 \\
\hline & & 1 & 3.44 & 3.57 & 3.63 & 3.65 & 3.42 & 3.53 & 3.56 & 3.64 \\
\hline & \multirow{4}{*}{0.25} & 0.25 & 4.57 & 4.63 & 4.66 & 4.67 & 4.55 & 4.60 & 4.63 & 4.65 \\
\hline & & 0.5 & 4.57 & 4.63 & 4.66 & 4.68 & 4.54 & 4.58 & 4.62 & 4.64 \\
\hline & & 0.75 & 4.13 & 4.28 & 4.35 & 4.37 & 4.11 & 4.25 & 4.33 & 4.35 \\
\hline & & 1 & 3.16 & 3.41 & 3.51 & 3.54 & 3.11 & 3.38 & 3.50 & 3.52 \\
\hline & \multirow{5}{*}{0.50} & 0.25 & 3.49 & 3.61 & 3.68 & 3.69 & 3.45 & 3.59 & 3.64 & 3.67 \\
\hline & & 0.5 & 3.49 & 3.61 & 3.68 & 3.69 & 3.44 & 3.58 & 3.63 & 3.67 \\
\hline & & 0.75 & 3.49 & 3.61 & 3.68 & 3.69 & 3.43 & 3.57 & 3.63 & 3.67 \\
\hline & & 1 & 3.16 & 3.41 & 3.51 & 3.54 & 3.12 & 3.38 & 3.50 & 3.52 \\
\hline & & 0.25 & 4.58 & 4.64 & 4.66 & 4.68 & 4.54 & 4.60 & 4.62 & 4.66 \\
\hline & \multirow{3}{*}{0.25} & 0.5 & 4.58 & 4.63 & 4.67 & 4.68 & 4.53 & 4.60 & 4.61 & 4.64 \\
\hline & & 0.75 & 4.11 & 4.28 & 4.35 & 4.38 & 4.10 & 4.25 & 4.32 & 4.32 \\
\hline & & 1 & 3.15 & 3.41 & 3.50 & 3.54 & 3.11 & 3.40 & 3.48 & 3.50 \\
\hline & \multirow{5}{*}{0.50} & 0.25 & 3.49 & 3.61 & 3.67 & 3.69 & 3.44 & 3.58 & 3.62 & 3.64 \\
\hline & & 0.5 & 3.49 & 3.61 & 3.68 & 3.69 & 3.42 & 3.56 & 3.61 & 3.63 \\
\hline & & 0.75 & 3.49 & 3.61 & 3.67 & 3.69 & 3.41 & 3.54 & 3.58 & 3.61 \\
\hline & & 1 & 3.15 & 3.41 & 3.51 & 3.54 & 3.10 & 3.36 & 3.52 & 3.52 \\
\hline & & 0.25 & 4.58 & 4.64 & 4.67 & 4.67 & 4.55 & 4.62 & 4.64 & 4.65 \\
\hline & \multirow{3}{*}{0.25} & 0.5 & 4.58 & 4.63 & 4.67 & 4.68 & 4.54 & 4.60 & 4.62 & 4.64 \\
\hline & & 0.75 & 4.11 & 4.28 & 4.35 & 4.37 & 4.08 & 4.24 & 4.31 & 4.35 \\
\hline & & 1 & 3.15 & 3.40 & 3.51 & 3.54 & 3.12 & 3.36 & 3.41 & 3.48 \\
\hline & \multirow{4}{*}{0.50} & 0.25 & 3.49 & 3.61 & 3.67 & 3.69 & 3.44 & 3.60 & 3.62 & 3.65 \\
\hline & & 0.5 & 3.48 & 3.61 & 3.67 & 3.69 & 3.43 & 3.60 & 3.61 & 3.63 \\
\hline & & 0.75 & 3.49 & 3.61 & 3.67 & 3.67 & 3.42 & 3.58 & 3.60 & 3.63 \\
\hline & & 1 & 3.15 & 3.40 & 3.51 & 3.54 & 3.13 & 3.38 & 3.49 & 3.51 \\
\hline
\end{tabular}




\section{Conclusions}

This paper has investigated the seismic bearing capacity of shallow foundations near slope using pseudo-static limit equilibrium analysis. Linear failure mechanism has been proposed to obtain pseudo-static bearing capacity coefficients of embedded strip footing near slope using limit equilibrium analysis. The PSO technique has been applied to obtain minimum bearing capacity coefficients.

Based on the present investigation, the following conclusions can be drawn:

1. $N_{\gamma E}$ values from the present analysis agreed well with other analyses reported by Askari and Farzaneh (2003), Sawada et al. (1994) and Yamamoto (2010). The present analysis shows a tendency to decrease $N_{\gamma E}$ values by increasing the horizontal seismic coefficient $\left(\mathrm{k}_{\mathrm{h}}\right)$ and vertical seismic coefficient $\left(\mathrm{k}_{\mathrm{v}}\right)$.

2. The seismic bearing capacity coefficient $N_{c s}$ was found relatively minor error value with previous researchers.

3. The minimum pseudo-static bearing capacity coefficients are presented in the form of design table for practical use in geotechnical engineering. It has been observed that the magnitude of bearing capacity coefficients decreases with an increase in slope inclination.

4. The seismic bearing capacity decreases with greater undrained shear strength ratio $\left(c_{1} / c_{2}\right)$ and the effect becomes more significant when the thickness of the top layer decreases.

5. The value of $N_{c s}$ increases with increasing $c_{1} / \gamma B_{0}$, whereas thiseffect recedes with an increase of $c_{1} / \gamma B_{0}$. Also,greater value of $c_{1} / \gamma B$ would decrease the effect of bottom layer.

Data availability statement: The authors confirm that some data and code generated during this study are proprietary or confidential and may only be provided with restrictions (e. g., PSO code).

\section{References}

Aote, S. S., Raghuwanshi, M. M., \& Malik, L. (2013). A brief review of particle swarm optimization: limitations \& future directions. International Journal of Computer Science Engineering (IJCSE), 2(5), 196-200.

Askari, F., and Farzaneh, O. (2003), “Upper-bound solution for Seismic bearing capacity of shallow foundation near slopes", Geotechniqe53(8), 697-702.
Baazouzi, M., Benmeddour, D., Mabrouki, A., and Mellas, M. (2016), “ $2 D$ numerical analysis of shallow foundation rested near slope under inclined loading”, Procedia Engineering, Elsevier, 143, 623634.

Budhu, M., and Al-Karni, A. (1993), "Seismic bearing capacity of soils", Geotechnique43(1): 181-187.

Button, S.J. (1953). "The bearing capacity of footings on two-layer cohesive subsoil." Proc. 3rd Intl. Conference on Soil Mechanics and Foundation Engrg., 1, Zurich: 332-335.

Castelli, F. and Lentini, V. (2012) Evaluation of the bearing capacity of footings on a slope. Int J Phys Model GeotechEng12(3):112-118

Chakraborty, D., and Kumar, J., (2013), “ Bearing Capacity of Foundations on slopes”, Geomechanics and Geoengineering, 8(4), 274285.

Chakraborty, D., and Kumar, J., (2014), “ Seismic Bearing Capacity of Shallow strip Footing Embedded in slope”, International Journal of Geomechanics, 6: 176-184

Cheng, Y. M., Li, L., and Chi, S. C. (2007). "Performance studies on six heuristic global optimization methods in the location ofcritical slip surface". ComputGeotech., 34(6):462-484. DOI:10.1016/j.compgeo.2007.01.004.

Choudhury, D., and Subba Rao, K. S. (2006), “Seismic bearing capacity of foundations on slopes”. Geotechnique, 53(3), 347-361

Choudhury, D., SubhaRao, K. S. (2005), " Seismic uplift capacity of inclined slip anchors”, Can Geotech. J., 42(1), 263-271.

Debnath, L. and Ghosh, S. (2018), "Pseudo-static analysis of shallow strip footingresting on two layered soil", International Journal of Geomechanics, ASCE, doi:10.1061/(ASCE)GM.19435622.0001049 .

Dormieux, L., and Pecker, A. (1995). " Seismic bearing capacity of foundations on cohesionless soil”, J. Geotech. Eng., ASCE, 121(3), 300-303

Engelbrecht AP (2007) Computational intelligence: an introduction.Wiley, London

Farzaneh O, Mofidi J, Askari F (2013) Seismic bearing capacity of strip footings near cohesive slopes using lower bound limit analysis. In: Proceedings of the 18th international conference on soil mechanics and geotechnical engineering, Paris, pp 1467-1470

Gbenga, D. E., \&Ramlan, E. I. (2016). Understanding the limitations of the particle swarm algorithm for dynamic optimization tasks: A survey towards the singularity of PSO for swarm robotic applications. ACM Computing Surveys (CSUR), 49(1), 8.

Hajihassani,M., Armaghani, J. D. and Kalatehjari, R. (2017). “Applications of Particle Swarm Optimizationin Geotechnical Engineering: A Comprehensive Review", Geotech. Geol. Eng. , Springer, DOI 10.1007/s10706-017-0356-z.

Hossain MS, El-Shafie A (2014) Evolutionary techniques versus swarm intelligence: application in reservoir release optimization. Neural ComputAppl 24(7):1583-1594. doi:10.

IS 1893-1984(Part 3), “Indian Standard Criteria for Earthquake Resistant Design of Structures”, Bureau of Indian Standards, New Delhi.

Kalatehjari, R. (2013). “An improvised three-dimensional slope stability analysis based on limit equilibrium method by using particle swarm optimization”. Dissertation, UniversitiTeknologi Malaysia.

Kennedy, J., and Eberhart, R. (1995). "Particle swarm optimization”, In Proceedings of IEEE international conference on neural networks 4, pp.1942-1948.

Kumar, J. (2003), “ $\mathrm{N} \gamma$ for rough strip footing using the method of characteristics”, Can. Geotech. J., 40(3), 669-674 
Kumar, J., and Ghosh, P. (2006). "Seismic bearing capacity for embedded footings on sloping ground." Geotechnique, 56(2), 133-140.

Kumar, J. and Kumar, N. (2003), " Seismic bearing capacity of rough footings on slopes using limit equilibrium”, Geotechnique, 53(3), 363-369

Kumar, J., and Rao, V. B.K. M. (2002), “ Seismic bearing capacity factors for spread foundations”, Geotechnique, 52(2), 79-88

Meyerhof, G. G. (1957), "The ultimate bearing capacity of foundation on slopes", In Proc. of 4th Int. Conf. on Soil Mech. and Found. Engg., London 1, 384-386

Meyerhof, G. G., and Hanna, A. M. (1978). Ultimate bearing capacity of foundations on layered soils under inclined load. Canadian Geotechnical Journal, 15(4), 565-572.

Michalowski, R. L., and Shi, L. (1995). Bearing capacity of footings over two-layer foundation soils. Journal of Geotechnical Engineering, 121(5), 421-428.

Mononobe, N., and Matsuo, H. (1929), "On the Determination of Earth pressure during Earthquakes", Proc. of the World Engineering Congress, Tokyo, 9, 179-87

Mononobe, N., and Matsuo, H. (1929). On the determination of earth pressure during earthquakes: Proceedings of the World Engineering Congress.

Okabe, S. (1924). The general theory on earth pressure and seismic stability of retaining wall and dam. Proc. Civil Engrg. Soc., Japan, 10(6), 1277-1323.

Paolucci, R. and Pecker, A. (1997), "Seismic bearing capacity of shallow strip foundations on dry soils", Soils Found., 37(3), 95-105

Prandtl, L. (1921), “ Umber die eindringungkeit plasticizer baustoffe und die festigkeit von schneiden”, Zeitschrift Fur AngewandtMathematik Und Mechanik, 1 (1), 15-30 (in German)

Purushothamaraj, P., Ramiah, B.K., and Venkatakrishna, K.N. (1974). "Bearing capacity of strip footings in two-layered cohesive-friction soils." Can. Geotech. J., 11: 32-45

Rankine, W. J. M. (1857), “ On the stability of Loose Earth”, Phil. Tras. Royal Society (London)

Reynolds CW (1987) Flocks, herds, and schools: a distributedbehavioral model. ACM SIGGRAPH Comput Gr21(4):25-34

Richards, R., Elms, D. G., and Budhu, M. (1993). “ Seismic Bearing Capacity and Settlement of Foundations”, J. Geotech. Eng., ASCE, 119(4): 662-674.

Saran, S., Sud, V. K., and Handa, S. C. (1989), "Bearing capacity of footings adjacent to slopes", J. Geotech. Eng., 115(4), 553-573

Sarma, S. K. (1999), “ Seismic bearing capacity of shallow strip footings adjacent to a slope", Proc., 2nd Int. Conf. Earthquake Geotechnical Engineering, Lisbon, Portugal, Balkema, Rotterdam, The Netherlands, 309-313.

Sarma, S. K., and lossifelis, I. S. (1990), " Seismic bearing capacity factors of shallow strip footings”, Geotechnique, 402, 265-273.

Sawada, T., Nomachi, S. G., and Chen, W. F. (1994), "Seismic bearing capacity of a mounded foundation near a downhill slope by pseudo-static analysis", Soils Found., 34(1), 11-17.

Soubra, A. H. (1999), “Upper bound solutions for bearing capacity of foundations”, J. Geotech. Geotech. Geoenviron. Eng., ASCE 125 (1): 59-69.

Terzaghi, K. (1943), “Theoretical Soil Mechanics”, Wiley

Yamamoto, K. (2010), "Seismic bearing capacity of shallow foundations near slopes using the upper-bound method", Int. J. Geotech. Engg., 4, 255-267.

Zhu, D. Y. (2000), "The least upper-bound solutions for bearing capacity factorN $\gamma$ ”, Soils. Found., 40(1), 123-129.
Jahani, M., Oulapour, M, andHaghighi, A.(2019).“Evaluation of the seismic bearing capacity ofshallow foundations located on the two-layered clayey soils."Iran J SciTechnol Trans Civ Eng. 43(1):49-57.

Xiao Y, et al.(2019).“Undrained bearing capacity of strip footings placed adjacent to twolayered slopes.” Int. J. Geomech;19(8).Doi:

Merifield, R. S., S. W. Sloan, and H. S. Yu. (1999). "Rigorous plasticity solutionsfor the bearing capacity of two-layered clays." Geotechnique 49 (4): 471-490. https://doi.org/10.1680/geot.1999.49.4.471.

Wu,G., Zhao, H., Zhao, M, and Xiao, Y. (2020). “ Undrained seismic bearing capacity of strip footing lying on two-layered slopetwo-layered slopes." Computer and Geotechnique 122: https://doi.org/10.1016/j.compgeo.2020.103539.

Vesic, A. S. (1975). "Bearing capacity of shallow foundations." In Foundation engineering handbook, edited by H. F. Winterkorn andH. Y. Fang, 144-165. New York: Van Nostrand Reinhold.

Kusakabe, O., T. Kimura, and H. Yamaguchi. (1981). "Bearing capacity of slopes under strip loads on the top surfaces." Soils. Found. 21 (4): $29-40$.

Georgiadis, K. (2010). "Undrained bearing capacity of strip footings on slopes.” J. Geotech. Geoenviron. Eng. 136 (5): 677-685. .

Narita, K., and H. Yamaguchi. (1990). "Bearing capacity analysis of foundations on slopes by use of log-spiral sliding surfaces." Soils Found. 30(3): 144-152. .

Xiao, Y., Zhao, M., Zhang, R., Zhao, H. and Wu, G. (2019). "Undrained Bearing Capacity of Strip Footings PlacedAdjacent to Two-Layered Slopes." Int. J. Geomech., ASCE, Doi: 10.1061/(ASCE)GM.19435622.0001480.

Cinicioglu, O. and Erkli, A. (2018)."Seismic bearing capacity of surficial foundations on sloping cohesive ground." Soil Dynamics and Earthquake Engineering, 111: 53-64.

Keshavarz, A., Beygi, M. and Vali, R. (2019). “Undrained seismic bearing capacity of strip footing placed on homogeneous and heterogeneous soil slopes by finite element limit analysis." Computers and Geotechnics, 113: 103094.

Wu, G., Eeri, M., Zhao, M. and Zhao, H. (2020). "Undrained seismic bearingcapacity of strip footingshorizontally embedded intwo-layered slopes." Earthquake Spectra, DOI: $10.1177 / 8755293020957332$.

\section{A Appendix I}

$$
\begin{gathered}
P_{A 1}=\frac{p_{L} B_{0}}{B_{0}+\boldsymbol{h}_{1}}\left(B_{0}-\boldsymbol{h}_{1} \cot \alpha_{A 1}\right) \\
\left\{\frac{\left(1-k_{v}\right) \sin \left(\alpha_{A 2}-\phi_{2}\right)+k_{h} \tan \phi_{1} \cos \left(\alpha_{A 2}-\phi_{2}\right)}{\cos \left(\alpha_{A 2}-\phi_{2}-\delta_{2}\right)}\right\} \\
+\frac{1}{2}\left(B_{0}-\boldsymbol{h}_{1} \cot \alpha_{A 1}\right) \boldsymbol{h}_{2} \gamma_{2} \\
\left\{\frac{\left(1-k_{v}\right) \sin \left(\alpha_{A 2}-\phi_{2}\right)+k_{h} \cos \left(\alpha_{A 2}-\phi_{2}\right)}{\cos \left(\alpha_{A 2}-\phi_{2}-\delta_{2}\right)}\right\} \\
+\gamma_{1} \boldsymbol{h}_{1}\left(B_{0}-\boldsymbol{h}_{1} \cot \alpha_{A 1}\right)
\end{gathered}
$$




$$
\left.\begin{array}{c}
\left\{\frac{\left(1-k_{v}\right) \sin \left(\alpha_{A 2}-\phi_{2}\right)+k_{h} \tan \phi_{1} \cos \left(\alpha_{A 2}-\phi_{2}\right)}{\cos \left(\alpha_{A 2}-\phi_{2}-\delta_{2}\right)}\right\} \\
-2 c_{2} \boldsymbol{h}_{2} \frac{\sin \left(\alpha_{A 2}-\phi_{2}\right)}{\cos \left(\alpha_{A 2}-\phi_{2}-\delta_{2}\right)} \\
-c_{2} \boldsymbol{h}_{2} \cot \alpha_{A 2} \frac{\cos \left(\alpha_{A 2}-\phi_{2}\right)}{\cos \left(\alpha_{A 2}-\phi_{2}-\delta_{2}\right)} \\
-c_{1}\left[\boldsymbol{h}_{1} \cot \alpha_{A 1} \frac{\cos \left(\alpha_{A 2}-\phi_{2}\right)}{\cos \left(\alpha_{A 2}-\phi_{2}-\delta_{2}\right)}-B_{0} \frac{\cos \left(\alpha_{A 2}-\phi_{2}\right)}{\cos \left(\alpha_{A 2}-\phi_{2}-\delta_{2}\right)}\right] \\
\left\{\begin{array}{l}
\left.\frac{\left(1-k_{v}\right) \sin \left(\phi_{2}+\alpha_{p 2}\right)-k_{h} \cos \left(\phi_{2}+\alpha_{p 2}\right)}{\cos \left(\phi_{2}+\alpha_{p 2}+\delta_{2}\right)}\right\} \\
+\gamma_{1} h_{1} h_{2} \cot \alpha_{p 2} \\
\left\{\frac{1}{2} h_{2}^{2} \cot \alpha_{p 2} \gamma_{2}\right. \\
\left.\left.+k_{v}\right) \sin \left(\phi_{2}+\alpha_{p 2}\right)+k_{h} \tan \phi_{1} \cos \left(\phi_{2}+\alpha_{p 2}\right)\right) \\
\cos \left(\phi_{2}+\alpha_{p 2}+\delta_{2}\right)
\end{array}\right\} \\
\left\{\frac{\left(h_{1} \cot \alpha_{p 1}+h_{2} \cot \alpha_{p 2}\right)}{\left(h_{1}+h_{1} \cot \alpha_{p 1}+h_{2} \cot \alpha_{p 2}\right)} h_{2} \cot \alpha_{p 2}\right. \\
+2 c_{2} h_{2}\left\{\frac{\sin \left(\phi_{2}+\alpha_{p 2}\right)}{\cos \left(\phi_{2}+\alpha_{p 2}+\delta_{2}\right)}\right\}+\sin \left(\phi_{2}+\alpha_{p 2}\right)+k_{h} \tan \phi_{1} \cos \left(\phi_{2}+\alpha_{p 2}\right) \\
\left.c_{2} h_{2} \cot \alpha_{p 2}\left\{\frac{\cos \left(\phi_{2}+\alpha_{p 2}\right)}{\cos \left(\phi_{2}+\alpha_{p 2}+\delta_{2}\right)}\right\} \frac{\cos \left(\phi_{2}+\alpha_{p 2}\right)}{\cos \left(\phi_{2}+\alpha_{p 2}+\delta_{2}\right)}\right\}
\end{array}\right\}
$$

\section{B Appendix II}

$$
\begin{aligned}
& a_{1}=\frac{\gamma_{1}}{\bar{\gamma}}\left\{\begin{array}{c}
\left(\frac{h_{1}}{B_{0}} \cot \alpha_{p 1}+2 \frac{h_{2}}{B_{0}} \cot \alpha_{p 2}\right) \frac{h_{1}}{B_{0}}- \\
\frac{1}{4}\left(h_{1} \cot \alpha_{p 1}+h_{2} \cot \alpha_{p 2}-\frac{D_{f}}{\tan i}+\frac{B_{0}}{2}\right)^{2} \tan \alpha_{p 1}
\end{array}\right\} \\
& \left\{\frac{\left(1-k_{v}\right) \sin \left(\phi_{1}+\alpha_{p 1}\right)-k_{h} \cos \left(\phi_{1}+\alpha_{p 1}\right)}{\cos \left(\phi_{1}+\alpha_{p 1}+\delta_{1}\right)}\right\} \\
& \left\{\frac{\left(1-k_{v}\right) \sin \left(\phi_{1}+\alpha_{p 1}\right)+k_{h} \tan \phi_{2} \cos \left(\phi_{1}+\alpha_{p 1}\right)}{\cos \left(\phi_{1}+\alpha_{p 1}+\delta_{1}\right)}\right\} \\
& +\left(\frac{h_{2}}{B_{0}}\right)^{2} \cot \alpha_{p 2} \frac{\gamma_{2}}{\bar{\gamma}}
\end{aligned}
$$

$$
\begin{aligned}
& \left\{\frac{\left(1-k_{v}\right) \sin \left(\phi_{2}+\alpha_{p 2}\right)-k_{h} \cos \left(\phi_{2}+\alpha_{p 2}\right)}{\cos \left(\phi_{2}+\alpha_{p 2}+\delta_{2}\right)}\right\} \\
& +2 \frac{\gamma_{1}}{\bar{\gamma}} \frac{h_{1}}{B_{0}} \frac{h_{2}}{B_{0}} \cot \alpha_{p 2} \\
& \left\{\frac{\left(1-k_{v}\right) \sin \left(\phi_{2}+\alpha_{p 2}\right)+k_{h} \tan \phi_{2} \cos \left(\phi_{2}+\alpha_{p 2}\right)}{\cos \left(\phi_{2}+\alpha_{p 2}+\delta_{2}\right)}\right\} \\
& -\left(2-\frac{h_{1}}{B_{0}} \cot \alpha_{A 1}\right) \frac{h_{1}}{B_{0}} \frac{\gamma_{1}}{\bar{\gamma}} \\
& \left\{\frac{\left(1-k_{v}\right) \sin \left(\alpha_{A 1}-\phi_{1}\right)+k_{h} \cos \left(\alpha_{A 1}-\phi_{1}\right)}{\cos \left(\alpha_{A 1}-\phi_{1}-\delta_{1}\right)}\right\} \\
& +2 \frac{\gamma_{1}}{\bar{\gamma}} \frac{h_{1}}{B_{0}}\left(1-\frac{h_{1}}{B_{0}} \cot \alpha_{A 1}\right) \\
& \left\{\frac{\left(1-k_{v}\right) \sin \left(\alpha_{A 1}-\phi_{1}\right)+k_{h} \tan \phi_{2} \cos \left(\alpha_{A 1}-\phi_{1}\right)}{\cos \left(\alpha_{A 1}-\phi_{1}-\delta_{1}\right)}\right\} \\
& -\left(1-\frac{h_{1}}{B_{0}} \cot \alpha_{A 1}\right) \frac{h_{2}}{B_{0}} \frac{\gamma_{2}}{\bar{\gamma}} \\
& \left\{\frac{\left(1-k_{V}\right) \sin \left(\alpha_{A 2}-\phi_{2}\right)+k_{h} \cos \left(\alpha_{A 2}-\phi_{2}\right)}{\cos \left(\alpha_{A 2}-\phi_{2}-\delta_{2}\right)}\right\} \\
& -2 \frac{\gamma_{1}}{\bar{\gamma}} \frac{h_{1}}{B_{0}}\left(1-\frac{h_{1}}{B_{0}} \cot \alpha_{A 1}\right) \\
& \left\{\frac{\left(1-k_{v}\right) \sin \left(\alpha_{A 2}-\phi_{2}\right)+k_{h} \tan \phi_{1} \cos \left(\alpha_{A 2}-\phi_{2}\right)}{\cos \left(\alpha_{A 2}-\phi_{2}-\delta_{2}\right)}\right\} \\
& b_{1}=2 \frac{\gamma_{1}}{\bar{\gamma}} \tan i\left(\frac{D_{f}}{B_{0} \tan i}-\frac{1}{2}\right)^{2} \\
& \left\{\frac{\left(1-k_{v}\right) \sin \left(\phi_{1}+\alpha_{p 1}\right)-k_{h} \cos \left(\phi_{1}+\alpha_{p 1}\right)}{\cos \left(\phi_{1}+\alpha_{p 1}+\delta_{1}\right)}\right\} \\
& -2 \frac{\gamma_{1}}{\bar{\gamma}} \frac{h_{2}}{B_{0}} \cot \alpha_{p 2} \frac{\tan \left(\frac{D_{f}}{B_{0}}-\frac{1}{2}\right) 2\left(\frac{D_{f}}{B_{0}}-\tan i\right)}{\left\{2 \frac{D_{f}}{B_{0}}+\tan \left(2 \frac{h_{1}}{B_{0}}-1\right)\right\}} \\
& \left\{\frac{\left(1-k_{v}\right) \sin \left(\phi_{1}+\alpha_{p 1}\right)+k_{h} \tan \phi_{2} \cos \left(\phi_{1}+\alpha_{p 1}\right)}{\cos \left(\phi_{1}+\alpha_{p 1}+\delta_{1}\right)}\right\} \\
& +2 \frac{\gamma_{1}}{\bar{\gamma}} \frac{h_{2}}{B_{0}} \cot \alpha_{p 2} \frac{\tan \left(\frac{D_{f}}{B_{0}}-\frac{1}{2}\right) 2\left(\frac{D_{f}}{B_{0}}-\tan i\right)}{\left\{2 \frac{D_{f}}{B_{0}}+\tan \left(2 \frac{h_{1}}{B_{0}}-1\right)\right\}} \\
& \left\{\frac{\left(1-k_{v}\right) \sin \left(\phi_{2}+\alpha_{p 2}\right)+k_{h} \tan \phi_{1} \cos \left(\phi_{2}+\alpha_{p 2}\right)}{\cos \left(\phi_{2}+\alpha_{p 2}+\delta_{2}\right)}\right\} \\
& d_{1}=2 \frac{c_{2}}{\bar{c}} \frac{h_{2}}{B_{0}} \frac{\sin \left(\phi_{2}+\alpha_{p 2}\right)}{\cos \left(\phi_{2}+\alpha_{p 2}+\delta_{2}\right)}+ \\
& \frac{c_{1}}{\bar{c}} \frac{h_{2}}{B_{0}} \cot \alpha_{p 2} \frac{\cos \left(\phi_{2}+\alpha_{p 2}\right)}{\cos \left(\phi_{2}+\alpha_{p 2}+\delta_{2}\right)}+ \\
& \frac{c_{2}}{\bar{c}} \frac{h_{2}}{B_{0}} \cot \alpha_{p 2} \frac{\cos \left(\phi_{2}+\alpha_{p 2}\right)}{\cos \left(\phi_{2}+\alpha_{p 2}+\delta_{2}\right)} \\
& +\frac{c_{1}}{\bar{c}} \frac{h_{1}}{B_{0}} \frac{\sin \left(\phi_{1}+\alpha_{p 1}\right)}{\cos \left(\phi_{1}+\alpha_{p 1}+\delta_{1}\right)} \\
& +\frac{c_{1}}{\bar{c}} \sin \alpha_{p 1}\left\{\frac{h_{1}}{2 B_{0}} \operatorname{cosec} \alpha_{p 1}-\frac{h_{2}}{2 B_{0}} \cot \alpha_{p 2} \sec \alpha_{p 1}+\right. \\
& \left.\frac{1}{2} \frac{D_{f}}{B_{0} \tan i} \sec \alpha_{p 1}-\frac{1}{4} \sec \alpha_{p 1}\right\}
\end{aligned}
$$




$$
\begin{aligned}
& \frac{\sin \left(\phi_{1}+\alpha_{p 1}\right)}{\cos \left(\phi_{1}+\alpha_{p 1}+\delta_{1}\right)}+\frac{c_{1}}{\bar{c}} \cot \alpha_{p 1} \\
& \left\{\frac{h_{1}}{2 B_{0}} \cos e c \alpha_{p 1}-\frac{h_{2}}{2 B_{0}} \cot \alpha_{p 2} \sec \alpha_{p 1}+\frac{1}{2} \frac{D_{f}}{B_{0} \tan i} \sec \alpha_{p 1}-\frac{1}{4} \sec \alpha_{p 1}\right\} \\
& \frac{\cos \left(\phi_{1}+\alpha_{p 1}\right)}{\cos \left(\phi_{1}+\alpha_{p 1}+\delta_{1}\right)}-\frac{c_{1}}{\bar{c}} \frac{h_{2}}{B_{0}} \cot \alpha_{p 2} \frac{\cos \left(\phi_{1}+\alpha_{p 1}\right)}{\cos \left(\phi_{1}+\alpha_{p 1}+\delta_{1}\right)} \\
& +2 \frac{c_{1}}{\bar{c}} \frac{h_{1}}{B_{0}} \frac{\sin \left(\alpha_{A 1}-\phi_{1}\right)}{\cos \left(\alpha_{A 1}-\phi_{1}-\delta_{1}\right)}+ \\
& \frac{c_{1}}{\bar{c}} \frac{h_{1}}{B_{0}} \cot \alpha_{A 1} \frac{\cos \left(\alpha_{A 1}-\phi_{1}\right)}{\cos \left(\alpha_{A 1}-\phi_{1}-\delta_{1}\right)} \\
& +\frac{c_{2}}{\bar{c}} \frac{\cos \left(\alpha_{A 1}-\phi_{1}\right)}{\cos \left(\alpha_{A 1}-\phi_{1}-\delta_{1}\right)}+ \\
& \frac{c_{2}}{\bar{c}} \frac{h_{1}}{B_{0}} \cot \alpha_{A 1} \frac{\cos \left(\alpha_{A 1}-\phi_{1}\right)}{\cos \left(\alpha_{A 1}-\phi_{1}-\delta_{1}\right)} \\
& +2 \frac{c_{2}}{\bar{c}} \frac{h_{2}}{B_{0}} \frac{\cos \left(\alpha_{A 2}-\phi_{2}\right)}{\cos \left(\alpha_{A 2}-\phi_{2}-\delta_{2}\right)} \\
& +\frac{c_{1}}{\bar{c}} \frac{\cos \left(\alpha_{A 2}-\phi_{2}\right)}{\cos \left(\alpha_{A 2}-\phi_{2}-\delta_{2}\right)} \\
& c_{1} h_{1} \cot \alpha_{A 1} \frac{\cos \left(\alpha_{A 2}-\phi_{2}\right)}{\cos \left(\alpha_{A 2}-\phi_{2}-\delta_{2}\right)} \\
& \overline{\bar{c}} \frac{1}{B_{0}} \cot \alpha_{A 1} \frac{\cos \left(\alpha_{A 2}-\phi_{2}-\delta_{2}\right)}{\cos \left(\alpha_{A 2}\right.} \\
& e_{1}=\left\{\frac{\left(1-k_{v}\right) \sin \left(\alpha_{A 1}-\phi_{1}\right)+k_{h} \cos \left(\alpha_{A 1}-\phi_{1}\right)}{\cos \left(\alpha_{A 1}-\phi_{1}-\delta_{1}\right)}\right\} \\
& -\left\{\frac{\left(1-\frac{h_{1}}{B_{0}} \cot \alpha_{A 1}\right)}{1+\frac{h_{1}}{B_{0}}}\right\} \\
& \left\{\frac{\left.\left(1-k_{v}\right) \sin \left(\alpha_{A 1}-\phi_{1}\right)+k_{h} \tan \phi_{2} \cos \left(\alpha_{A 1}-\phi_{1}\right)\right)}{\cos \left(\alpha_{A 1}-\phi_{1}-\delta_{1}\right)}\right\} \\
& +\left\{\frac{\left(1-\frac{h_{1}}{B_{0}} \cot \alpha_{A 1}\right)}{1+\frac{h_{1}}{B_{0}}}\right\} \\
& \left\{\frac{\left(1-k_{v}\right) \sin \left(\alpha_{A 2}-\phi_{2}\right)+k_{h} \tan \phi_{1} \cos \left(\alpha_{A 2}-\phi_{2}\right)}{\cos \left(\alpha_{A 2}-\phi_{2}-\delta_{2}\right)}\right\}
\end{aligned}
$$

